\title{
Reviews of the genera Schaefferia Absolon, 1900, Deuteraphorura Absolon, 1901, Plutomurus Yosii, 1956 and the Anurida Laboulbène, 1865 species group without eyes, with the description of four new species of cave springtails (Collembola) from Krubera-Voronya cave, Arabika Massif, Abkhazia
}

\author{
Rafael Jordana $^{1}$, Enrique Baquero ${ }^{1 *}$, Sofía Reboleira ${ }^{2}$ and Alberto Sendra ${ }^{3}$ \\ ${ }^{1}$ Department of Zoology and Ecology, University of Navarra, 31080 Pamplona, Spain \\ e-mails: rjordana@unav.es; ebaquero@unav.es *Corresponding author. \\ ${ }^{2}$ Department of Biology, Universidade de Aveiro and CESAM \\ Campus Universitário de Santiago, 3810-193 Aveiro, Portugal \\ e-mail: sreboleira@ua.pt \\ ${ }^{3}$ Museu Valencià d'Història Natural (Fundación Entomológica Torres Sala) \\ Paseo de la Pechina 15. 46008 Valencia, Spain \\ e-mail: alberto.sendra@uv.es
}

Received on November 4, 2011. Accepted on November 21, 2011

\begin{abstract}
Summary
Krubera-Voronya cave and other deep systems in Arabika Massif are being explored during many speleological expeditions. A recent Ibero-Russian exploration expedition (summer of 2010) took place in this cave with the aim of providing a study of the biocenosis of the deepest known cave in the world. Four new species of Collembola were found at different depths: Schaefferia profundissima n. sp., Anurida stereoodorata $\mathrm{n}$. sp., Deuteraphorura kruberaensis $\mathrm{n}$. sp., and Plutomurus ortobalaganensis $\mathrm{n}$. sp., the last one at $-1980 \mathrm{~m}$ deep. The identification and description of the new species have required the careful study of all congeneric species, implying a revision of each genus. As a result of this work tables and keys to all significant characters for each species are presented.
\end{abstract}

\section{Keywords}

Key; cavernicolous fauna; biospeleology; deepest cave of the world; Schaefferia profundissima n. sp.; Anurida stereoodorata n. sp.; Deuteraphorura kruberaensis n. sp.; Plutomurus ortobalaganensis n. sp.

\section{Introduction}

Collembola (springtails) are common inhabitants of caves and more than 240 species are considered troglobionts in the Euro-Mediterranean region (Deharveng and Thibaud 
1989; Thibaud and Massoud 1986; Thibaud and Dehanverg 1994), but they also are found in cold caves at high elevations. Collembola play an important role in the terrestrial environments of many subterranean communities, frequently consisting of stable and large populations of tiny arthropods feeding on fungi and decomposing organic matter. Until now the deepest-dwelling springtails were Ongulonychiurus colpus Thibaud and Massoud, 1986 and Tritomurus veles Lukić, Houssin and Deharveng, 2010, found in caves in Spain (-550 m below ground level, bgl) and Croatia (-430 m bgl) respectively (Thibaud and Massoud 1986; Lukić et al. 2010). But a new discovery of a new species of Plutomurus (Tomoceridae) at $-1980 \mathrm{~m}$ deep in Krubera-Voronya cave (also called Voronya Cave or Voronja Cave), the deepest cave of the world reaching the $-2191 \mathrm{~m} \mathrm{bgl}$ (Figure 1, entrance; Figure 2, cave profile), located in the Arabika massif (Western Caucasus), one of the largest karstic massifs in the World. This massif, well-developed at elevations ranging between 1900 and $2500 \mathrm{~m}$ above sea level, asl, is composed of Lower Cretaceous and Upper Jurassic limestone's (Klimchouk 2005). Although Krubera-Voronya cave and other deep systems in Arabika Massif, have been explored during many speleological expeditions, especially in the last decade, but their biological components have received little interest.

During the summer of 2010, an Ibero-Russian exploration expedition in the Krubera-Voronya cave took place including a biospeleological study of the biocenosis of the deepest cave on Earth. The objective was to understand the vertical distribution

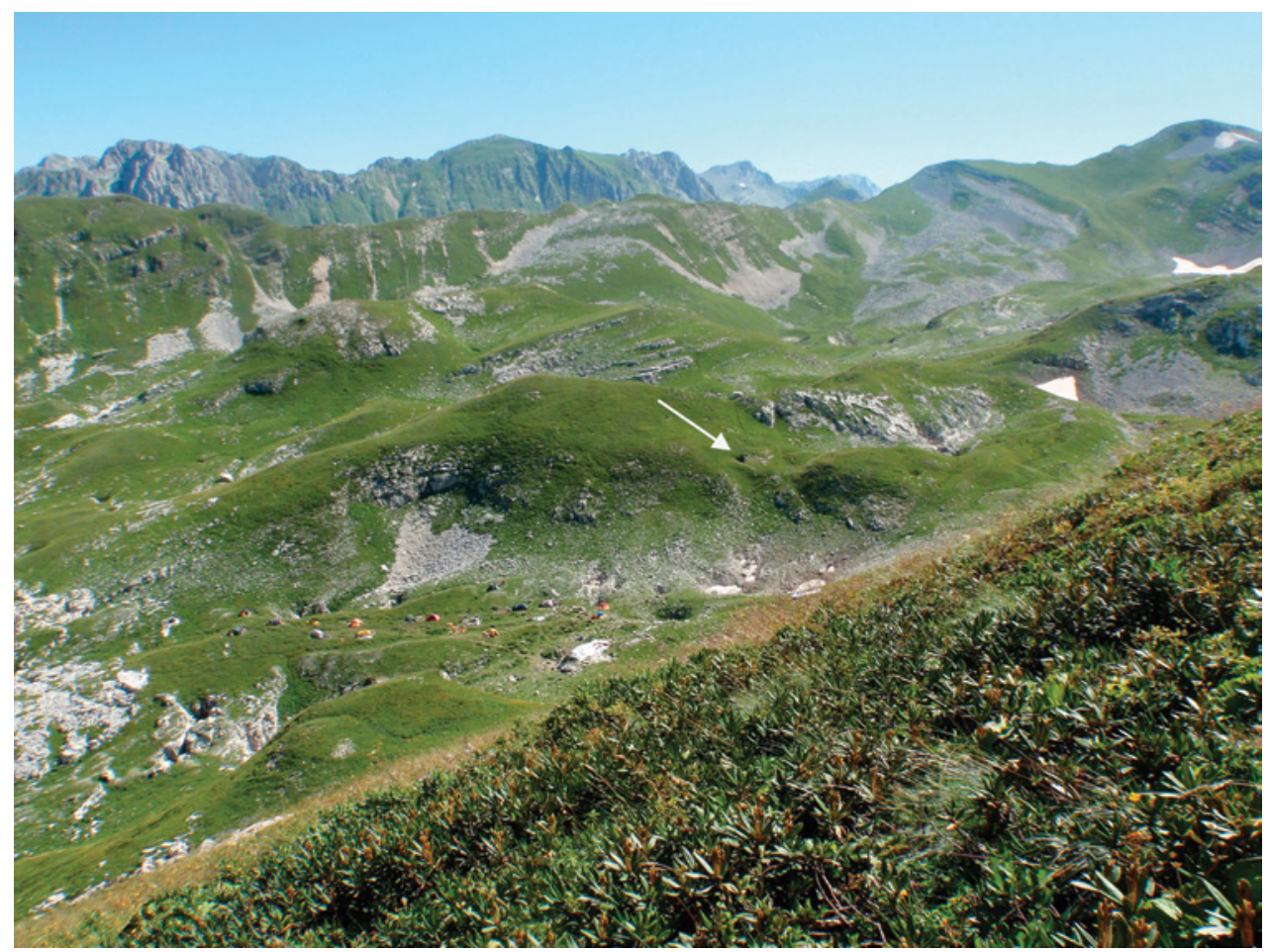

Figure 1. Krubera-Voronya cave entrance. Photo by Sofía Reboleira. 


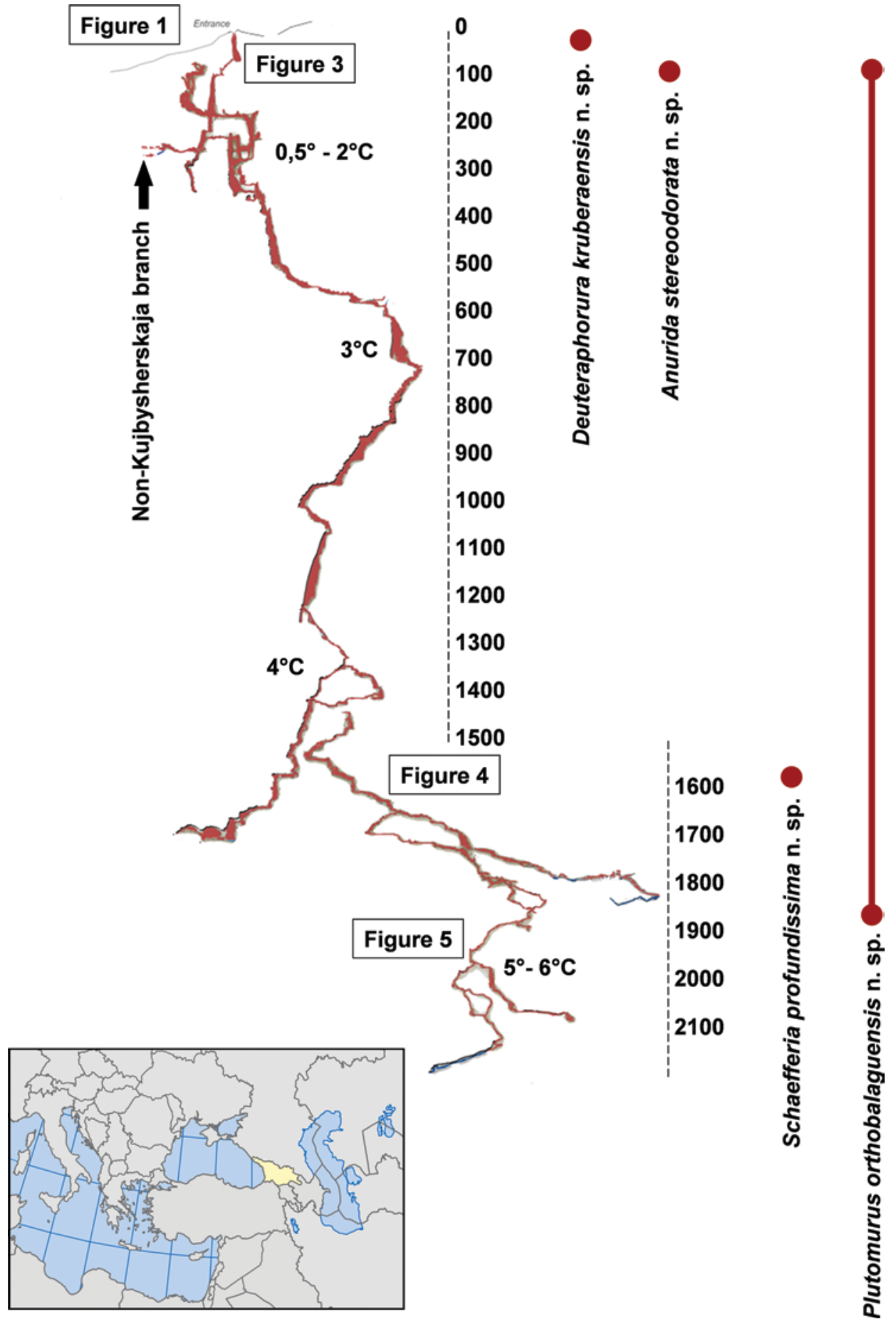

Figure 2. Krubera-Voronya cave profile, location of Figures 1, 3-5, and locations at which new species were found (red dots and red line). Adapted from Ukrainian Speleological Association 2010, compiled by A. Klimchouk. 
of the invertebrate fauna in the deepest underground natural place known on Earth (Sendra and Reboleira, unpublished). This lead to the discovery of the species described in the present work which are now the deepest invertebrates ever found below the surface of the Earth. Three other new species have been found at different depths in the same cave.

Despite Krubera-Voronya cave is also inhabited by other hypogean arthropods possessing different degrees of troglomorphy (Sendra and Reboleira, unpublished), but still Collembola play a very important rule in the decomposition and consumer of organic matter. The described new species were found to be the most abundant secondary decomposers in the terrestrial environment of the cave.

In this environment, and at different depths, have appeared, in addition to the new species of Plutomurus, new species of Schaefferia (Hypogastruridae), Anurida (Pseudachorutinae) and Deuteraphorura (Onychiurinae).

\section{Materials and methods}

Field work was conducted in the Krubera-Voronya cave (UTM: $43^{\circ} 24^{\prime} 35^{\prime \prime} \mathrm{N}, 40^{\circ} 21^{\prime}$ $\left.44^{\prime \prime} \mathrm{E}\right)$ to a depth of $-2140 \mathrm{~m}$ bgl by the Ibero-Russian CaveX Team. The cave is located in a disputed political entity on the eastern shore of the Black Sea, southwest of the Caucasus. The cave was monitored for almost one month (from 27.VII.2010 to 24.VIII.2010), from the base of the first shaft, in total darkness at $-15 \mathrm{~m}$ bgl, to the deepest part of the cave, at the last siphon at $-2140 \mathrm{~m}$ bgl. Sets of pitfall traps $(6 \mathrm{~cm}$ diameter and $7 \mathrm{~cm}$ deep, with $1 \mathrm{~cm}$ diameter tube fixed inside at the centre) were used in the base of the first series of shafts (Figure 3) and in each bivouac $(-700 \mathrm{~m},-1400 \mathrm{~m}$ and $-1690 \mathrm{~m} \mathrm{bgl}$ ) (Figures 4 and 5). Traps were partially filled with 1.2-propanodiol, and cheese was used as a lure. The traps were supported and covered by small stones in order to prevent flooding. The monitoring of pitfalls was supplemented by several hours of active searching during the visit to the cave.

Specimens were cleared in Nesbitt's fluid and, after washing for one hour in $70 \%$ alcohol, were mounted in Hoyer's medium for optical microscope observation. Some specimens were observed with an scanning electron microscope, SEM. Specimens from $70 \%$ ethyl alcohol, were slowly rehydrated in a decreasing series of ethyl alcohol. Once in distilled water they were fixed in $4 \%$ glutaraldehyde in cacodylate buffer for $24 \mathrm{~h}$, and then transferred to sucrose $0.25 \mathrm{M}$ for $24 \mathrm{~h}$. After this time the specimens are dehydrated up to $100 \%$ ethyl alcohol. Complete desiccation was achieved by the $\mathrm{CO}_{2}$ critical point technique. Samples then were covered by a $16 \mathrm{~nm}$ thin layer of molecular gold using an Emitech K550 sputter coater. Observations were done with a Zeiss Digital Scanning Microscope 940 A.

\section{Cave description}

The entrance of Krubera-Voronya cave is located at $2240 \mathrm{~m}$ asl at $15 \mathrm{~km}$ from the Black Sea, through an open air pit of $-60 \mathrm{~m} \mathrm{bgl} \mathrm{depth} \mathrm{in} \mathrm{the} \mathrm{slope} \mathrm{of} \mathrm{the} \mathrm{valley.}$ 


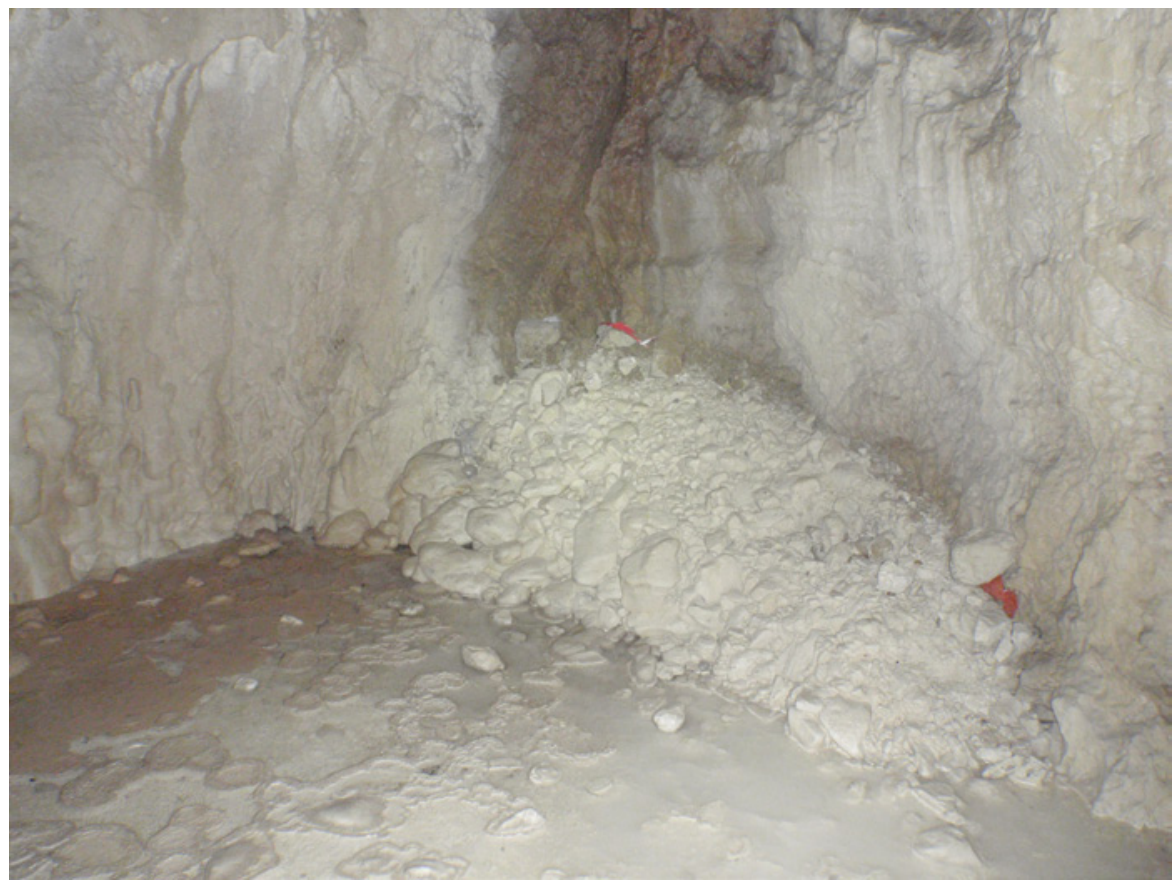

Figure 3. Location of two or the pitfall traps at $-70 \mathrm{~m}$ bgl. Photo by Sofía Reboleira.

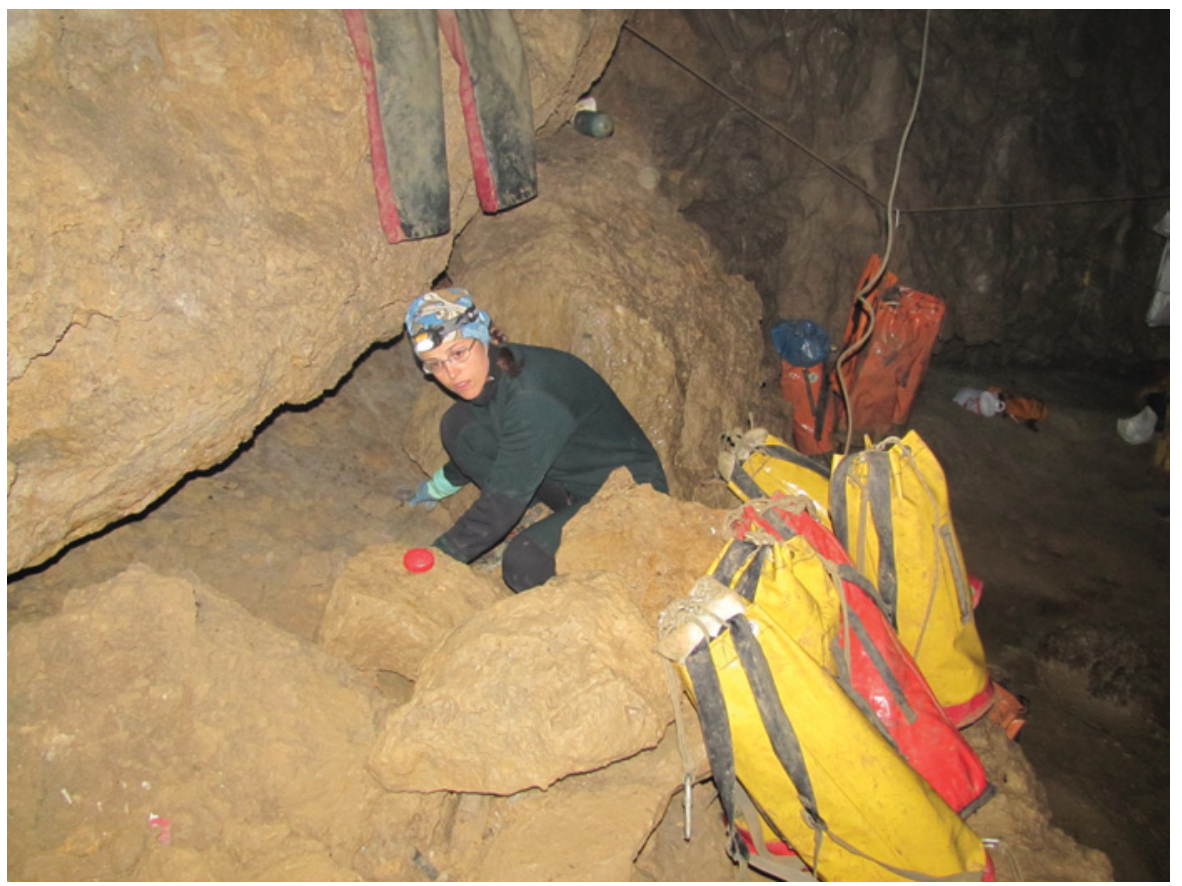

Figure 4. Bivouc at $-1600 \mathrm{~m}$ bgl. Photo by Sergio Garcia-Dils. 


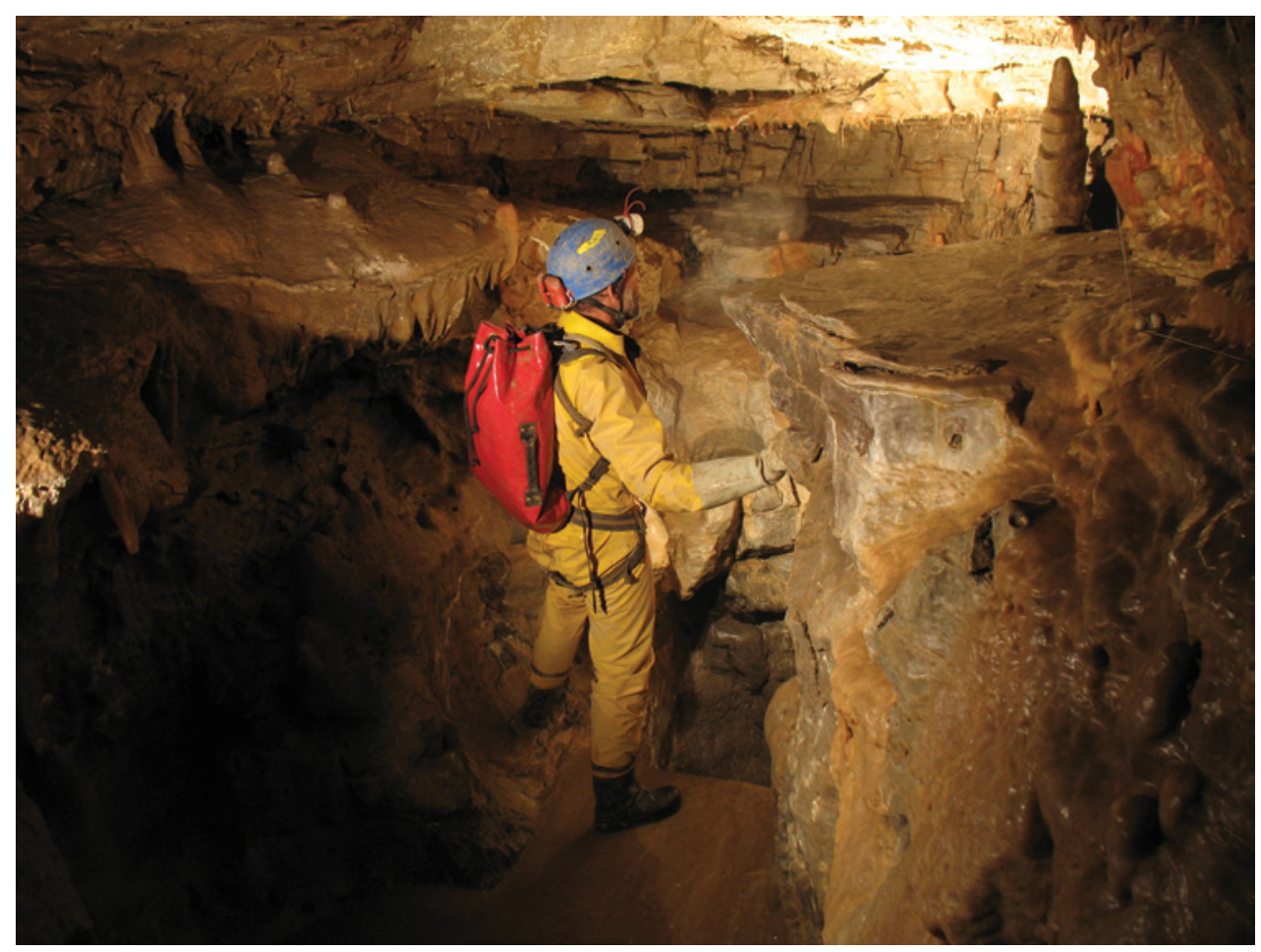

Figure 5. The cave at $-1980 \mathrm{~m}$ bgl, the deepest habitat of Plutomurus ortobalaganensis $\mathrm{n}$. sp. Photo by Denis Provalov.

The cave (Figure 2) has two main branches of strictly vertical pits separated by short meanders. At - $1400 \mathrm{~m}$ bgl, in the main branch of the cave, requires cave-diving techniques are required to pass several siphons to the current end of the dry cave, in a last siphon at a depth of $-2140 \mathrm{~m}$ bgl.

The cave atmosphere has a very constant temperature throughout the year. During the sampling period was possible to record a vertical gradient, increasing from the $0.5^{\circ} \mathrm{C}$ in the upper part of the cave, to $5-6^{\circ} \mathrm{C}$ at $-2000 \mathrm{~m}$ bgl (García Dils, pers. comm.). The water flow that goes down by gravity is constant along the cave, which allows deposition of organic matter to the deepest parts of the cave in a short period of time.

\section{Systematic entomology}

The following abbreviations are used in this section: Abd I-VI, abdominal segment I-VI; Ant I-IV, Antennal segments I-IV; asl, above sea level; bgl, below ground level; ms, microsensillum/a; PAO, postantennal organ; s, sensillum; Th I-III, thoracic segment I-III. 


\section{Schaefferia profundissima Jordana and Baquero n. sp.}

(Figures 6-8)

\section{Type locality}

Krubera Cave, Arabika Massif, Gagrinsky Range of the Western Caucasus, Gagra district of Abkhazia (Ortobalagan).
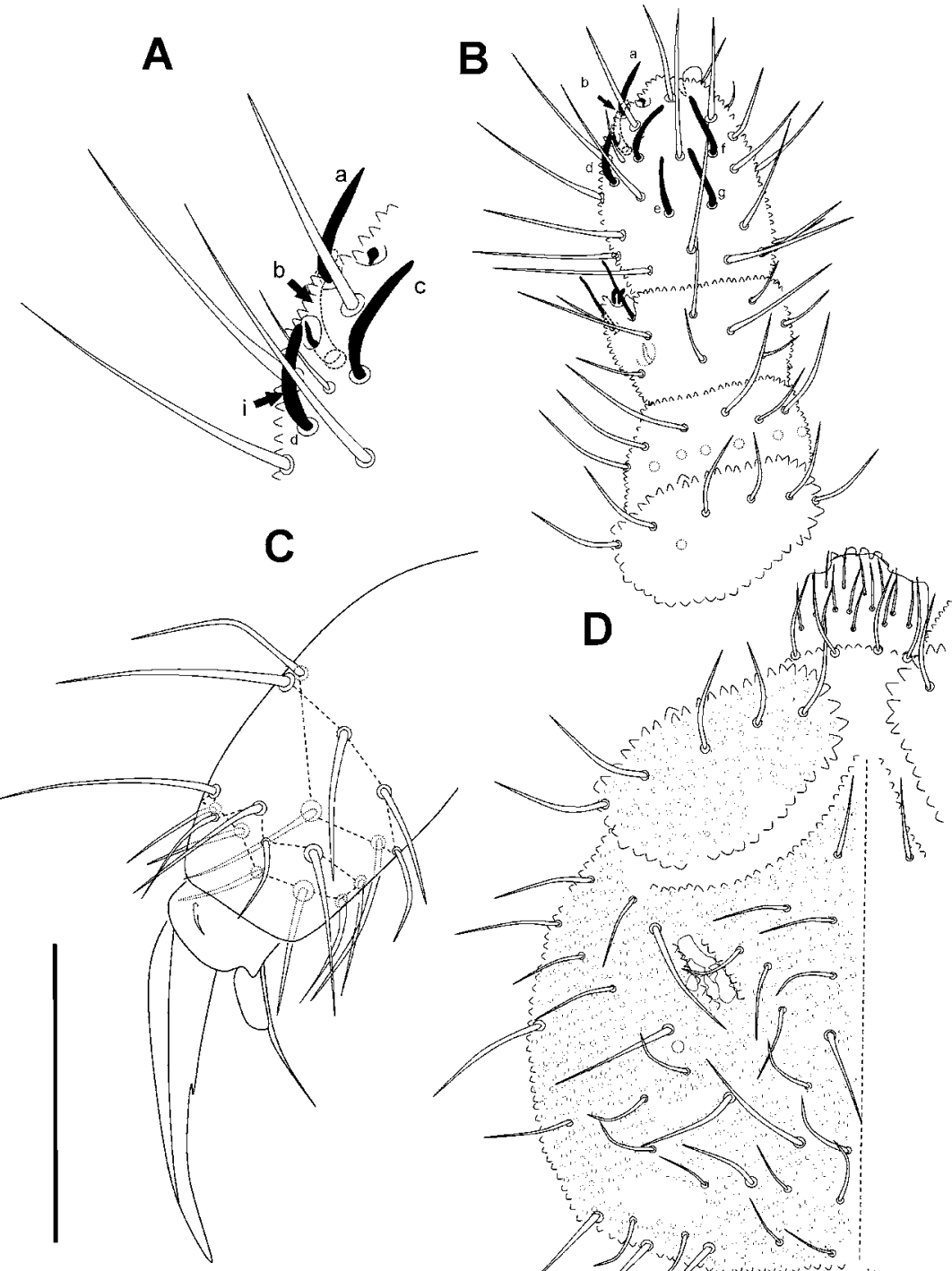

Figure 6. Schaefferia profundissima n. sp. (A) Detail of antennal tip (some cylindrical blunt chaetae are named using the nomenclature of Jordana et al. 1997). (B) Antennae. (C) Leg III. (D) Dorsal head. 


\section{Type material}

Holotype (male) on slide, $-1600 \mathrm{~m}$ from entrance (that it is at $2420 \mathrm{~m}$ asl), shelter 1 , from pitfall trap, between 26.VII.2010 to 24.VIII.2010. Coordinates: lat $43.409722^{\circ}$, long $40.362222^{\circ}\left(43^{\circ} 24^{\prime} 35.00^{\prime \prime} \mathrm{N}, 40^{\circ} 21^{\prime} 44.00^{\prime \prime E}\right)$. CaveX Team leg. Paratypes (5) on slides ( 2 males, 2 females and 1 juvenile), same data as holotype. Deposited in Museu de Valencia (Holotype and 4 Paratypes) and MZNA (1 Paratypes).

\section{Description}

Body length: holotype $1.11 \mathrm{~mm}$ (mean of 6 specimens $=0.93 \mathrm{~mm}$ ). Habitus typical of Hypogastruridae with reduced eyes and furca, fusiform body and differentiated macro and mesochaetae. Yellowish ground colour without any spot of dark pigmentation. Ant I with 6 dorsal cylindrical blunt chaetae. Ant II with 6 dorsal and 6 ventral chaetae in a single row, Ant III sensory organ with 2 central short rods flanked by 2 longer guard sensilla and a small sensillum in a ventral pit, Ant IV with a simple apical vesicle, 7 sensilla or cylindrical blunt chaetae (a, b, c, d, e, f and g) (after Jordana et al. 1997), sub-apical ms and apical sensory peg (Figures 6A-B). 0 to 1 eyes on each side of the head ( 1 specimen with $0+0,3$ specimens with $0+1$, and 2 specimens with $1+1)$, each eye similar in size to the $\mathrm{PAO}$ accessory tubercle, $\mathrm{PAO}$ with 4 vesicles (Figure 6D, 8C). Labrum with 4 prelabral chaetae and 5, 5, 4 labral chaetae. Tibiotarsi I-III with 19, 19, 18 chaetae respectively, without capitate tenent hair. Unguis with tooth at the middle of the internal edge. Unguiculus with basal lamella and an apical filament reaching the middle of the unguis edge (Fig 6C). Unguis $50 \mu \mathrm{m}$ long. Ventral tube with $3+3$ apical chaetae. Retinaculum with $4+4$ teeth. Dens length $92 \mu$ m, with 5 chaetae. Mucro $(34 \mu \mathrm{m})$ near $1 / 3$ as dens length (Figure $7 \mathrm{~A})$. Anal spines on papillae not fused, of same length as the unguis of leg III (Figure 7B).

\section{Chaetotaxy (Figures 8A-D)}

Head: $\mathrm{d}_{2}-\mathrm{d}_{5}\left(\mathrm{a}_{0}, \mathrm{~d}_{0}\right.$ and $\mathrm{d}_{1}$ absent $), \mathrm{sd}_{1}-\mathrm{sd}_{5}, \mathrm{v}_{1}-\mathrm{v}_{2}, \mathrm{c}_{1}-\mathrm{c}_{5}, \mathrm{p}_{1}-\mathrm{p}_{5} . \mathrm{d}_{2}, \mathrm{v}_{2}, \mathrm{oc}_{1}, \mathrm{oc}_{3}, \mathrm{~g}_{5}, \mathrm{p}_{3}$ and $\mathrm{p}_{4}$ are macrochaetae. Th I with $3+3$ chaetae. Th II-III with $\mathrm{a}_{1}-\mathrm{a}_{6}, \mathrm{~m}_{1}, \mathrm{~m}_{4}-\mathrm{m}_{6}$ (with $\mathrm{ms}), \mathrm{p}_{1}-\mathrm{p}_{4}(\mathrm{~s}), \mathrm{p}_{5}-\mathrm{p}_{6}$. Abd I with $5+5$ chaetae between $\mathrm{p}_{5} \mathrm{~s}$ in rows "a" and " $\mathrm{m}$ ". Abd II-III with 5-7 + 5-7 chaetae between $p_{5}(s)$ in rows "a" and " $m$ ". Abd IV with $7+7$ chaetae between $\mathrm{p}_{5}(\mathrm{~s})$ in rows " $\mathrm{a}$ " and " $\mathrm{m}$ ", and chaeta $\mathrm{p}_{1}$ shorter than $\mathrm{p}_{2}$. Abd V with $2+2$ chaetae between $\mathrm{p}_{3}(\mathrm{~s})$ on row "a". Abd VI with $\mathrm{a}_{1}-\mathrm{a}_{3}, \mathrm{p}_{1}$ (anal spine), $\mathrm{p}_{2}-\mathrm{p}_{3}$ and $\mathrm{p}_{0}$ present (chaetotaxy follows Jordana et al. 1997).

\section{Discussion}

Thirty-four species of Schaefferia have been described around the world, mostly in the Palearctic Region with only four species on the Nearctic Region. Thibaud et al. (2004) considered only 28 of them as valid species, synonymising some species. We have revalidated some of these species as due to differences in chaetotaxy. The specimens found by Babenko et al. (1994) from Caucasus identified as S. vandalica have differences in chaetotaxy on Abd II-IV compared with the original description for the 


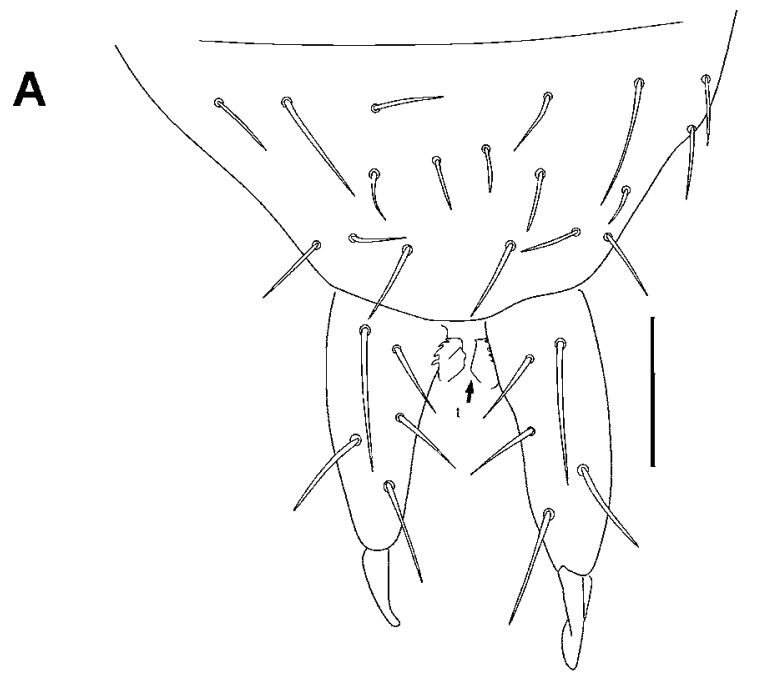

B

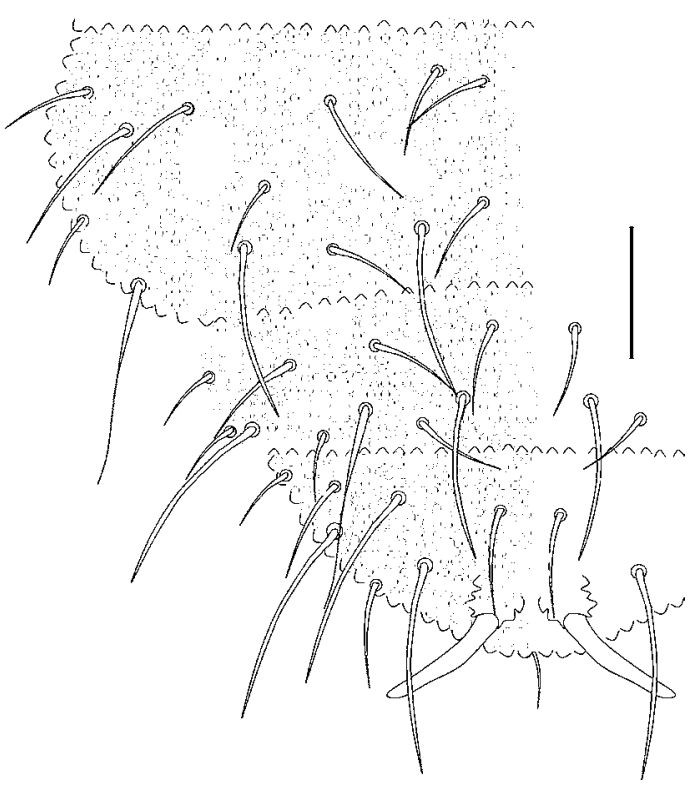

Figure 7. Schaefferia profundissima n. sp. (A) Furca (t, tenaculum). (B) Dorsal view of Abd IV-VI, showing small areas without granulation.

species. Again, the specimens identified as $S$. duodecimocellata from Alaska $(2700 \mathrm{~m}$ asl) by Fjellberg (1985), differs in Abd IV chaetotaxy from the original description of S. duodecimocellata.

In the key given below all these species can be separated. The new species has been compared with those with 0-1 eyes: S. coeca Cassagnau, 1959, S. guerrerense (Bonet, 1945), S. oaxacana Palacios-Vargas and Thibaud, 1985, and S. subcoeca Deharveng and Thibaud, 1980. The new species shares with $S$. oaxacana the presence of mucron, but 


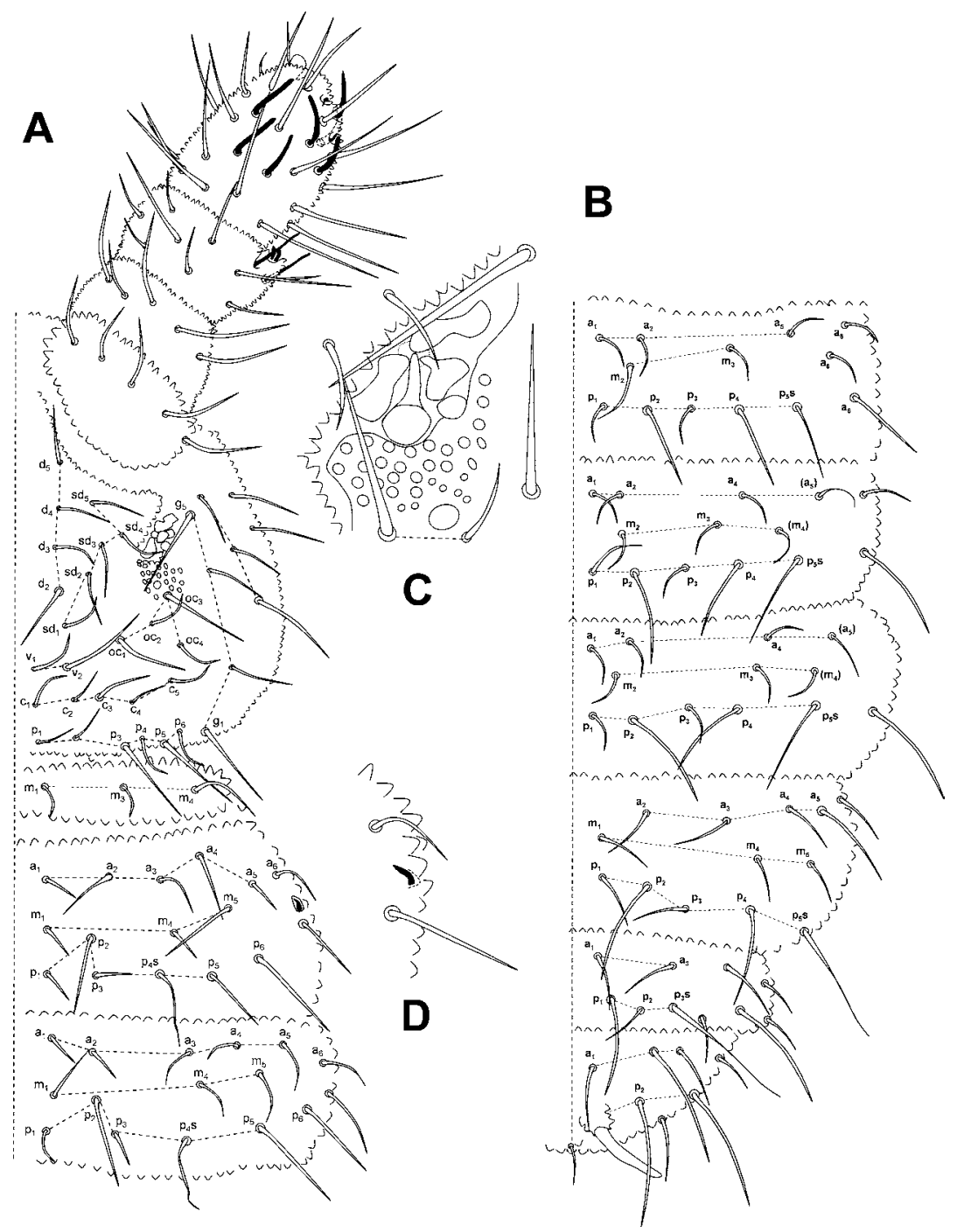

Figure 8. Schaefferia profundissima n. sp. chaetotaxy. (A) Dorsal head (with antenna) and Th. (B) Dorsal Abd. (C) Detail of PAO and granulation beside it. (D) Detail of the ms of Th II.

differs from it by the number of chaetae on dens and sensilla on Ant IV. For the preparation of the characters' tables, the original papers and some reviews for the genus has been consulted (see Table 1). 


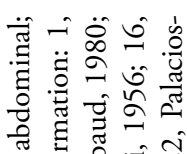
ते 过节产

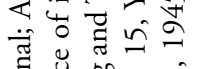

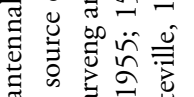

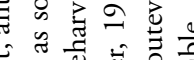

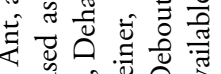
$\because 气 N \tilde{D}$

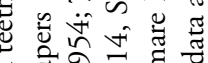

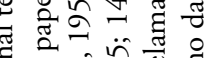

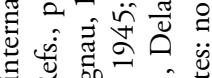
$\Xi \widetilde{4}$

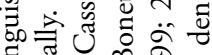
$\Xi$.

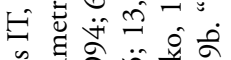

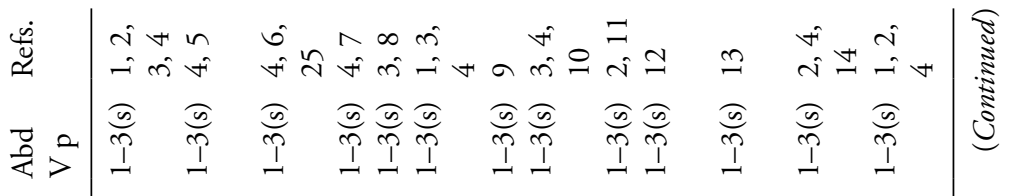

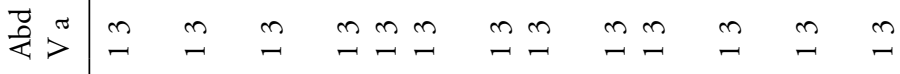

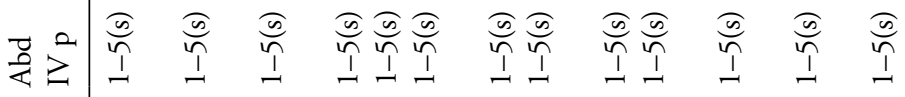

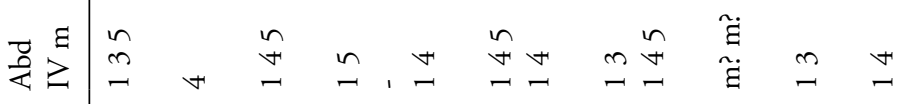

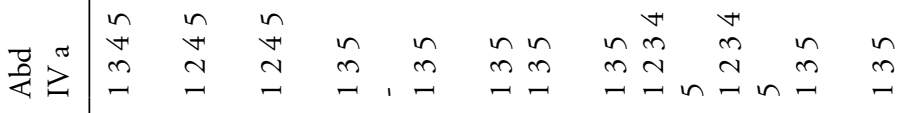

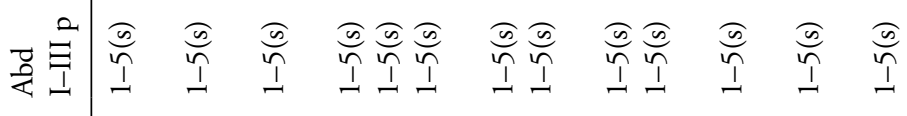

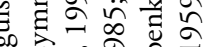

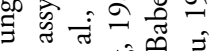
है

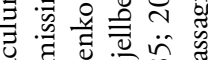

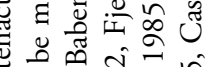

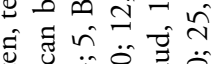
- $\ddot{+} \ddot{\circ} \tilde{\sigma}$

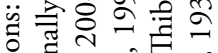

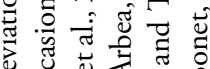

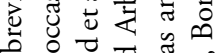

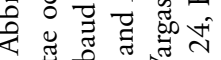

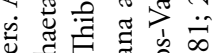

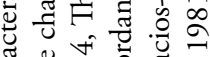

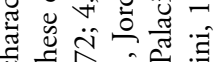
ป

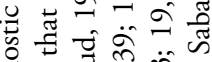

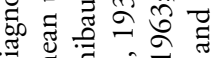
急 芦 品的芯芯

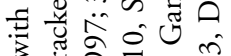

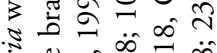
$\approx \tilde{\infty} \approx \dot{\infty}$ 这获

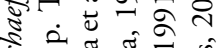
फे फ 记을

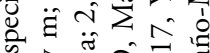
के हैँ -

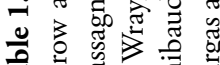

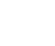

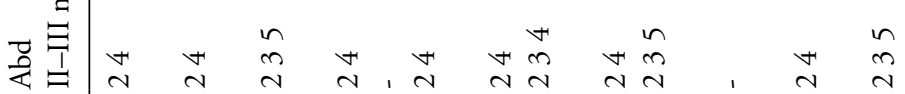

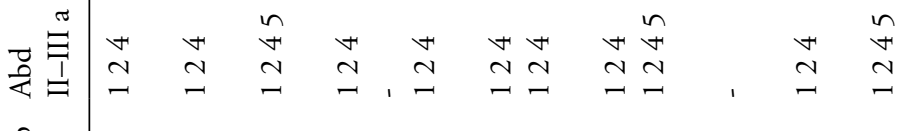

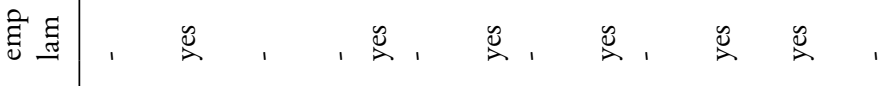

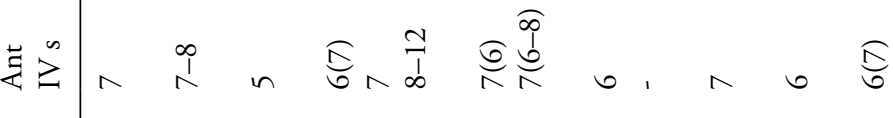

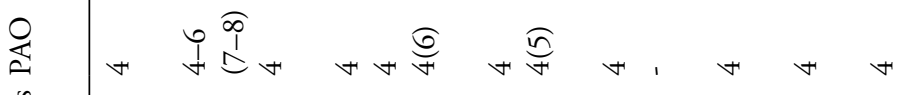

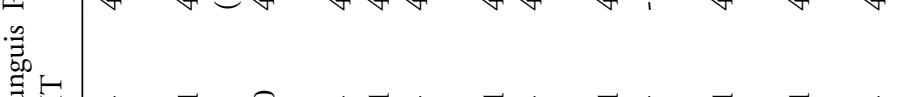
$\Xi \models$ ～

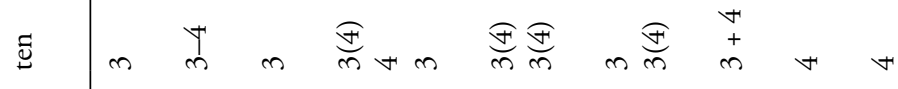

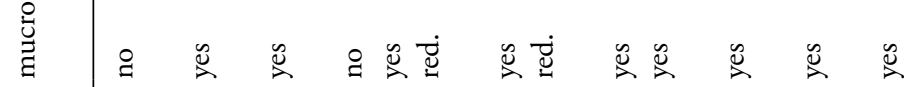

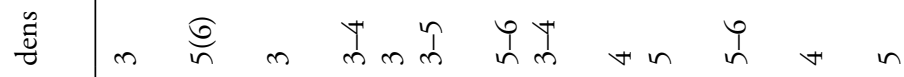

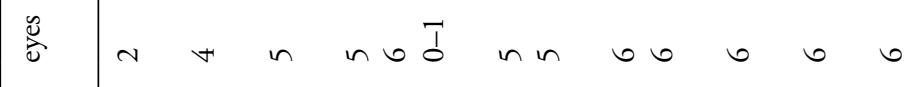

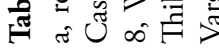
| 


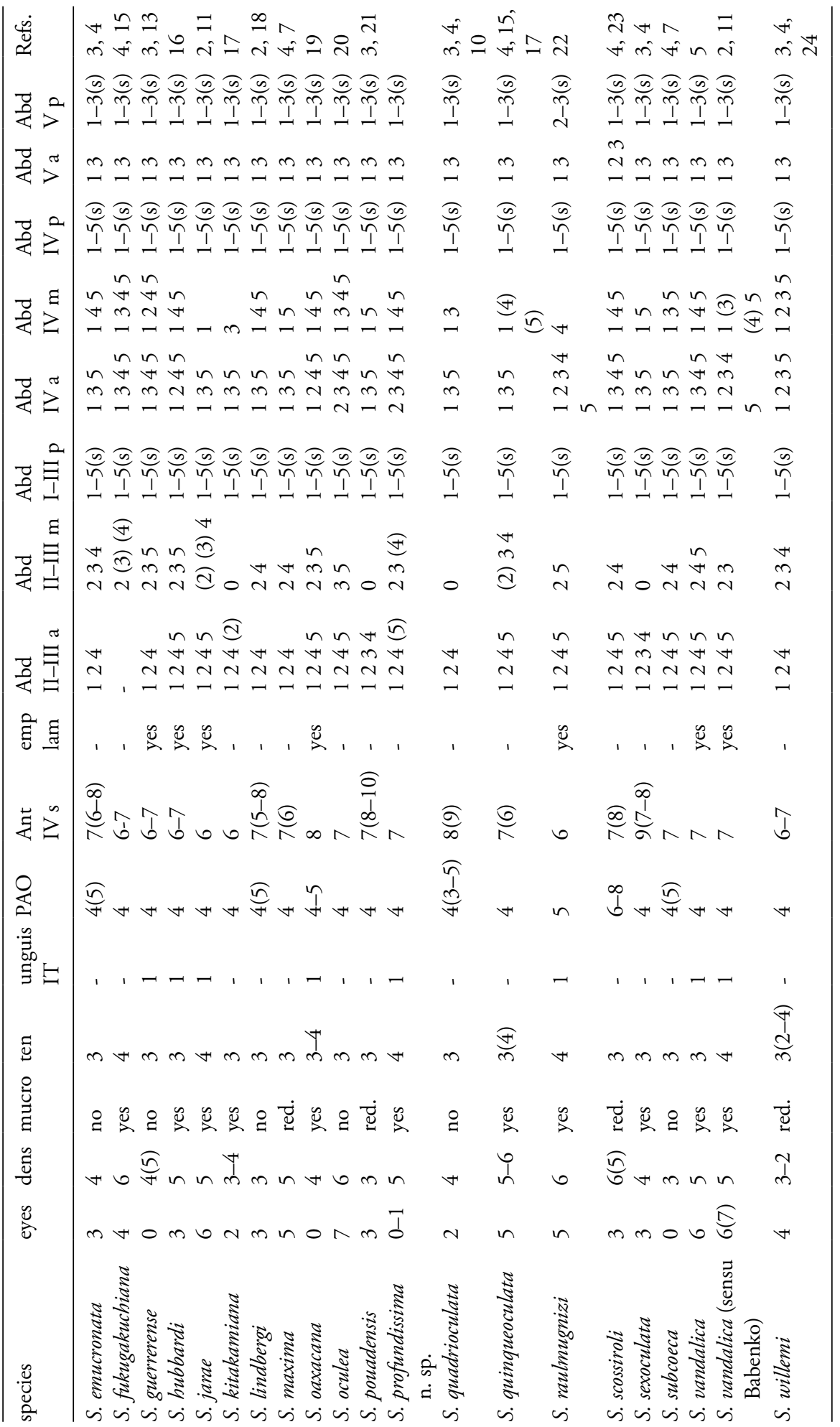


Key to the world species of Schaefferia

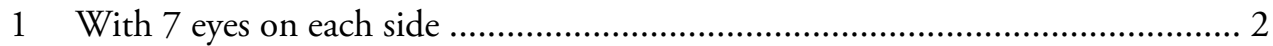

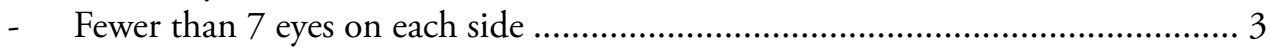

2 Without mucro .......................................... S. oculea Babenko, 1999 (Russia, soil) With mucro ........... S. vandalica (Jordana and Arbea, 1990) (Sierra Morena, soil)

3 With 6 eyes on each side ............................................................................... 4

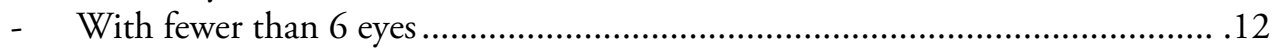

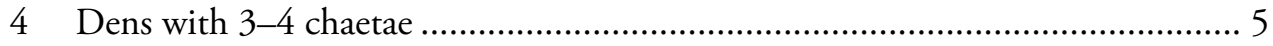

- Dens with more than 4 chaetae ......................................................................... 7

5 Tenaculum with 3 teeth.

S. dehanvergi (Jordana and Arbea, 1990) (Pyrenees, soil)

66 sensilla on Ant IV

S. duodecimoculata (Steiner, 1955) sensu Thibaud et al., 2004 (Spain, soil)

- 7 sensilla on Ant IV ......................................... S. cheoha Wray, 1963 (USA, cave)

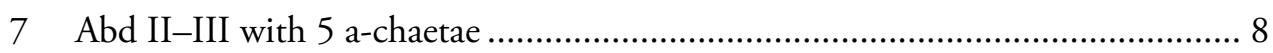

- Abd II-III with 3-4 a-chaetae .............................................................. 9

8 Abd II-III with 2 m-chaetae.

S. vandalica Jordana and Arbea, 1990 (Sierra Morena, soil)

- $\quad$ Abd II-III with 3 m-chaetae.

S. duodecimocellata Bonet, 1945 sensu Fjellberg, 1984 (Alaska)

9 Abd II-III with 3 a-chaetae .......... S. duodecimocellata Bonet, 1945 (Mexico, soil)

- Abd II-III with 4 a-chaetae ..................................................................... 10

10 Tenaculum with 3 teeth; Abd IV with 3 m-chaetae

S. vandalica sensu Babenko nec Jordana and Arbea, 1990 (Caucasus, soil)

- Tenaculum with 4 teeth; Abd IV with fewer than 3 m-chaetae ......................... 11

11 Abd IV with 1 m-chaeta.........S. jarae (Jordana and Arbea, 1990) (Pyrenees, soil)

- Abd IV with 2 m-chaetae .................. . elegans (Cassagnau, 1959) (Pyrenees, soil)

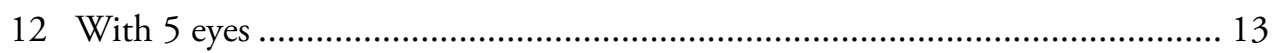

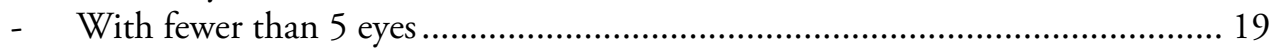

13 Unguis without inner tooth..........S. bidentata (Cassagnau, 1954) (Pyrenees, soil)

- Unguis with inner tooth ............................................................................ 14

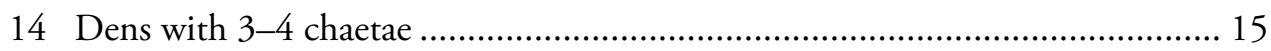

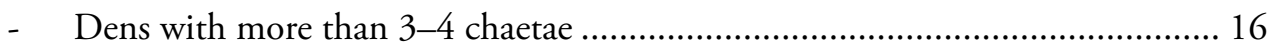

15 Abd II with 2 m-chaetae.

S. canigouensis Deharveng and Thibaud, 1980 (Pyrenees, soil)

- Abd II with 3 m-chaetae............... S. decemoculata (Stach, 1939) (Germany, cave) 
$16 \mathrm{PAO}$ with 5 lobes

.. S. raulmugnizi Palacios-Vargas and Castaño-Meneses, 2008 (Mexico, soil)

- $\quad$ PAO with 4 lobes

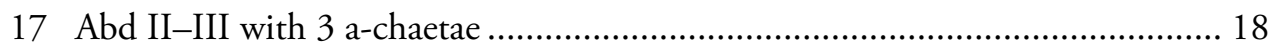

- Abd II-III with 4 a-chaetae .................S. quinqueoculata Yosii, 1956 (Japan, cave)

18 Abd IV with 2 m-chaetae

S. maxima Deharveng and Thibaud, 1980 (Pyrenees, soil)

- $\quad$ Abd IV with 3 m-chaetae ................... S. czernovi Martynova, 1978 (Siberia, soil)

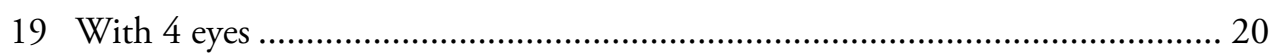

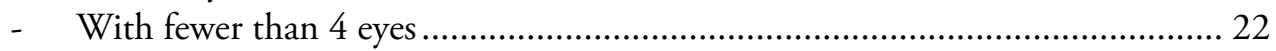

20 Dens with 3-4 chaetae; mucro reduced

S. willemi (Bonet, 1930) (Belgium, cave)

- Dens with more than 4 chaetae ......................................................................... 21

21 PAO with 4 multi-branched lobes; Abd IV with 1 m-chaeta $\left(\mathrm{m}_{4}\right)$

S. baschkirica Kniss, 1985 (Russia, cave)

- $\quad$ PAO with 4 simple lobes; Abd IV with 4 m-chaetae... S. fukugakuchiana (Yosii, 1956) (Japan, cave)

22 With 3 eyes ……......................................................................................... 23

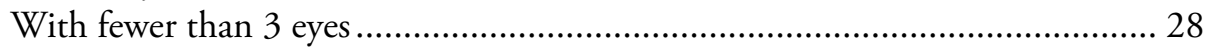

23 PAO with 6-8 lobes ................. S. scossirolii Dallai and Sabatini, 1981 (Italy, soil)

PAO with fewer than 6 lobes.......................................................................... 24

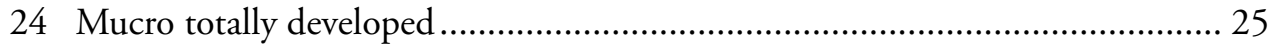

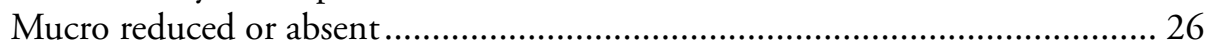

25 Dens with 5 chaetae .............................. S. hubbardi Thibaud, 1995 (USA, cave) Dens with 4 chaetae ...................... S. sexoculata (Gisin, 1947) (Switzerland, soil)

26 Mucro reduced; Abd II-III with 4 chaetae in rows "a" and "m" together.

S. pouadensis Delamare Deboutteville, 1945 (France, cave)

- Mucro absent; Abd II-III with 5 or 6 chaetae in rows " $a$ " and " $m$ " together..... 27

27 Dens with 4 chaetae; Abd II-III with 6 chaetae in rows "a" and " $m$ " together...... S. emucronata Absolon, 1900 (Czechia, cave)

- Dens with 3 chaetae; Abd II-III with 5 chaetae in rows "a" and " $m$ " together...... S. lindbergi Gama, 1963 (Portugal, cave)

28 With 2 eyes

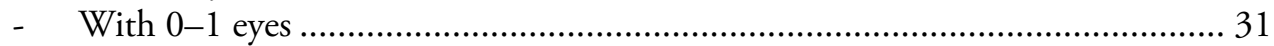

29 With mucro; Ant IV with 6 sensilla.

S. kitakamiana Yosii, 1991 (Japan, cave)

- Without mucro; Ant IV with 7-9 sensilla. 30 
30 Dens with 4 chaetae; Abd II-III with 3 chaetae in rows "a" and " $m$ " together S. quadrioculata (Stach, 1939) (Germany, cave)

- Dens with 3 chaetae; Abd II-III with 5 chaetae in rows "a" and " $m$ " together S. ariegica Cassagnau, 1959 (France, soil)

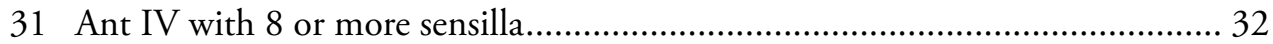

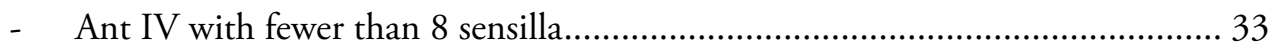

32 Mucro well developed; Abd II-III with 7 chaetae in rows "a" and " $m$ " together... S. oaxacana Palacios-Vargas and Thibaud, 1985 (Mexico, cave)

- Mucro reduced; Abd II-III with 5 chaetae in rows "a" and "m" together. S. coeca Cassagnau, 1959 (France, soil)

33 Mucro well developed; 0-1 eyes S. profundissima n. sp. (Caucaso, cave)

- Without mucro; eyes absent 34

34 Dens with 4-5 chaetae; Abd IV with 8 chaetae in rows "a" and " $m$ " together. S. guerrerense (Bonet, 1945) (Mexico, cave)

- Dens with 3 chaetae; Abd IV with 6 chaetae in rows "a" and " $m$ " together. S. subcoeca Deharveng and Thibaud, 1980 (France, soil)

\section{Anurida stereoodorata Jordana and Baquero n. sp.}

(Figures 9-11)

\section{Type locality}

Krubera Cave (called too Voronya Cave or Voronja Cave), Arabika Massif, Gagrinsky Range of the Western Caucasus, Gagra district of Abkhazia (Ortobalagan).

\section{Type material}

Holotype (female) on slide, $-70 \mathrm{~m}$ from entrance ( $2420 \mathrm{~m}$ above sea level), pitfall trap, between 26.VII.2010 to 24.VIII.2010. Coordinates: lat $43.409722^{\circ}$, long $40.362222^{\circ}$ $\left(43^{\circ} 24^{\prime} 35.00^{\prime \prime} \mathrm{N}, 40^{\circ} 21^{\prime} 44.00^{\prime \prime E}\right.$ ). CaveX Team leg. 4 paratypes (female) on two slides, 2 paratypes on SEM stub and 104 paratypes in ethyl alcohol. Deposited in Museu de Valencia (Holotype and 90 Paratypes) and MZNA (19 Paratypes).

\section{Etymology}

The name "stereoodarata" derives from the orientation forward of the two chemoreceptors $(\mathrm{PAO})$.

\section{Description}

Paratergites on Th and Abd lobed laterally, Abd VI bilobed (Figures 10A, 11A). Holotype (female) length $3.90 \mathrm{~mm}$; paratypes up to $4.5 \mathrm{~mm}$. Colour in alcohol 


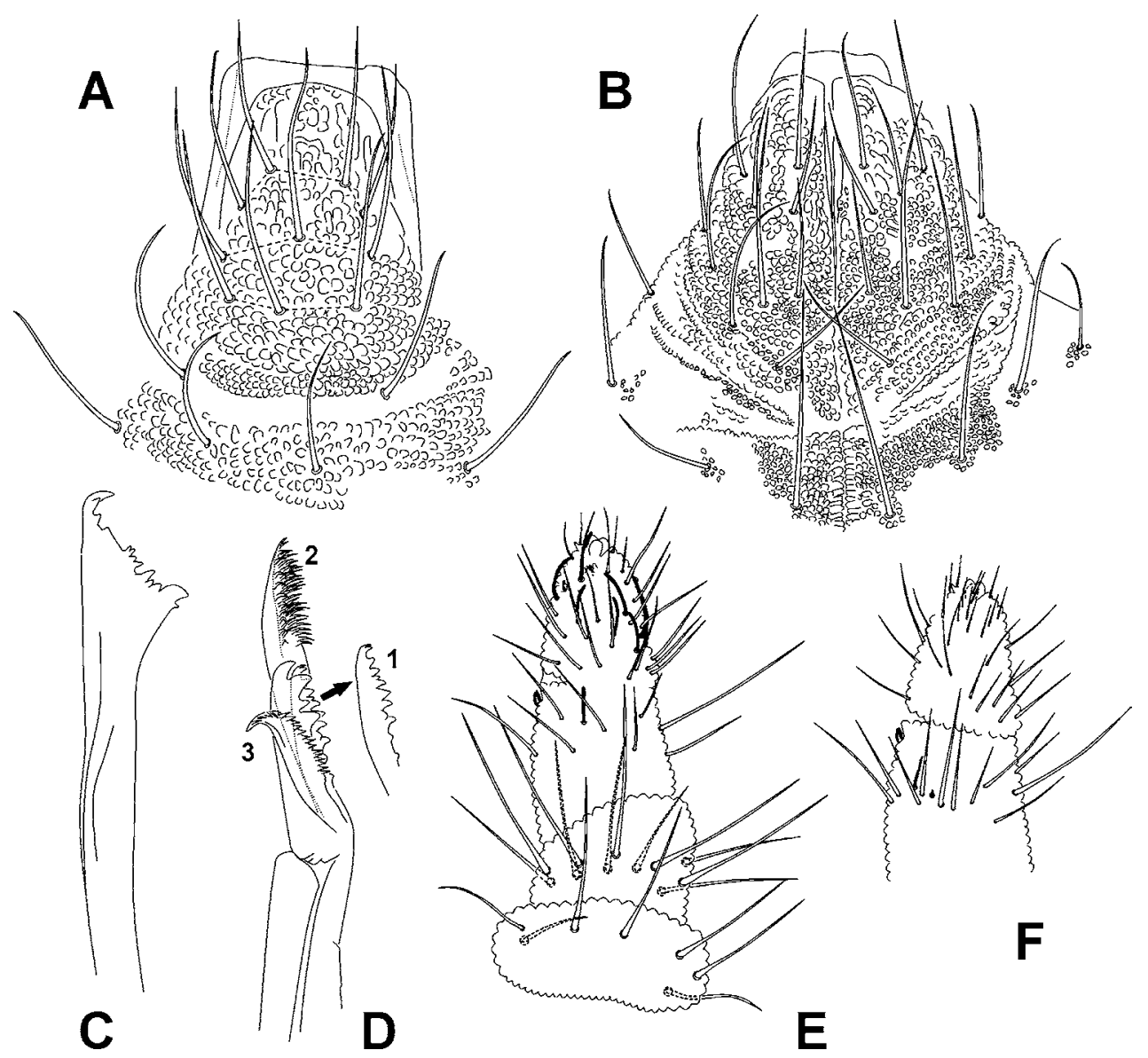

Figure 9. Anurida stereoodorata n. sp. (A) Labrum. (B) Labium. (C) Mandible. (D) Maxillar lamellae (after Fjellberg 1985). (E) Antenna. (F) detail of antenna, ventral view.

whitish. Eyes absent. Labral formula interpreted as 4/2334 (Figure 9A). Antennae/ head ratio 0.65 . Antennal segment IV with 7 blunt sensilla and trilobed apical bulb (Figures 9E-F). External ms and subapical organite present. Antennal segments III and IV fused dorsally. Sensory organ of antennal segment III consisting of two long, widely separated outer sensilla, a small ventral ms and two straight and pointed sensory pegs (Figure 11B). Antennal segment II with 11 chaetae, antennal segment I with 7 chaetae. PAO (Figures 11C-D), dome shaped, with about 60 vesicles with chemoreceptor aspect in its frontal part (Figure 11C-E), directed forward, and probably with stereoolfactory ability given their position and the environment in which this species lives, in darkness. Mandible with 3 teeth and dentate plate, 10-13 teeth in total (Figure 9C). Maxillary capitulum with a four teeth unguis and three dentate or fringed lamellae (Figure 9D). Labium with 10 chaetae on each side, without papillate $\mathrm{L}$ chaeta (Figure 9B). Th I-III and Abd I-IV with lobed laterally paratergites. Female genital plate with 20-26 microchaetae; male genital plate with about 80 microchaetae. Unguis without inner teeth (Figure 10D). Furca completely absent. 


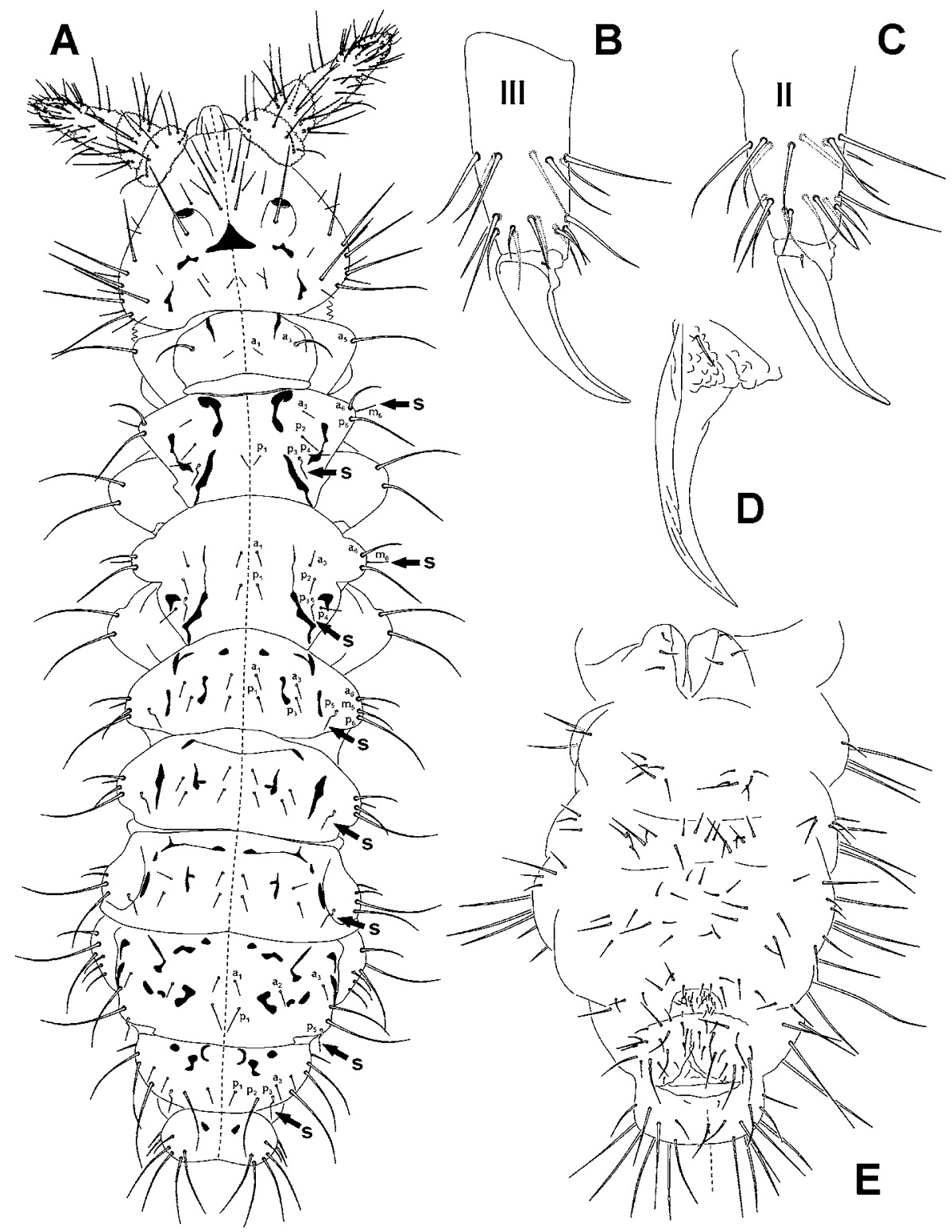

Figure 10. Anurida stereoodorata n. sp. (A) Habitus, dorsal view. The black spots means crevices and depressions (see Figure 11A) (the arrows point to the 'sensory' chaetae) (B-C) Legs III and II respectively. (D) Unguis, lateral view. (E) Ventral view of Abd.

\section{Chaetotaxy (Figures 10A, 10E)}

Macro and microchaetae on body well differentiated; lateral macrochaetae well developed. Th I with $3+3$ chaetae; Th II with 8 chaetae, 'sensory' chaetae $\mathbf{s}=\mathrm{m}_{6}$ and $\mathrm{p}_{3}$ (the term 'sensory' not implying that they have any special sensory function); thoracic terga III with 9 chaetae, 'sensory' chaetae $s=\mathrm{m}_{6}$ and $\mathrm{p}_{3}$; Abd I-III with 9 chaetae. 


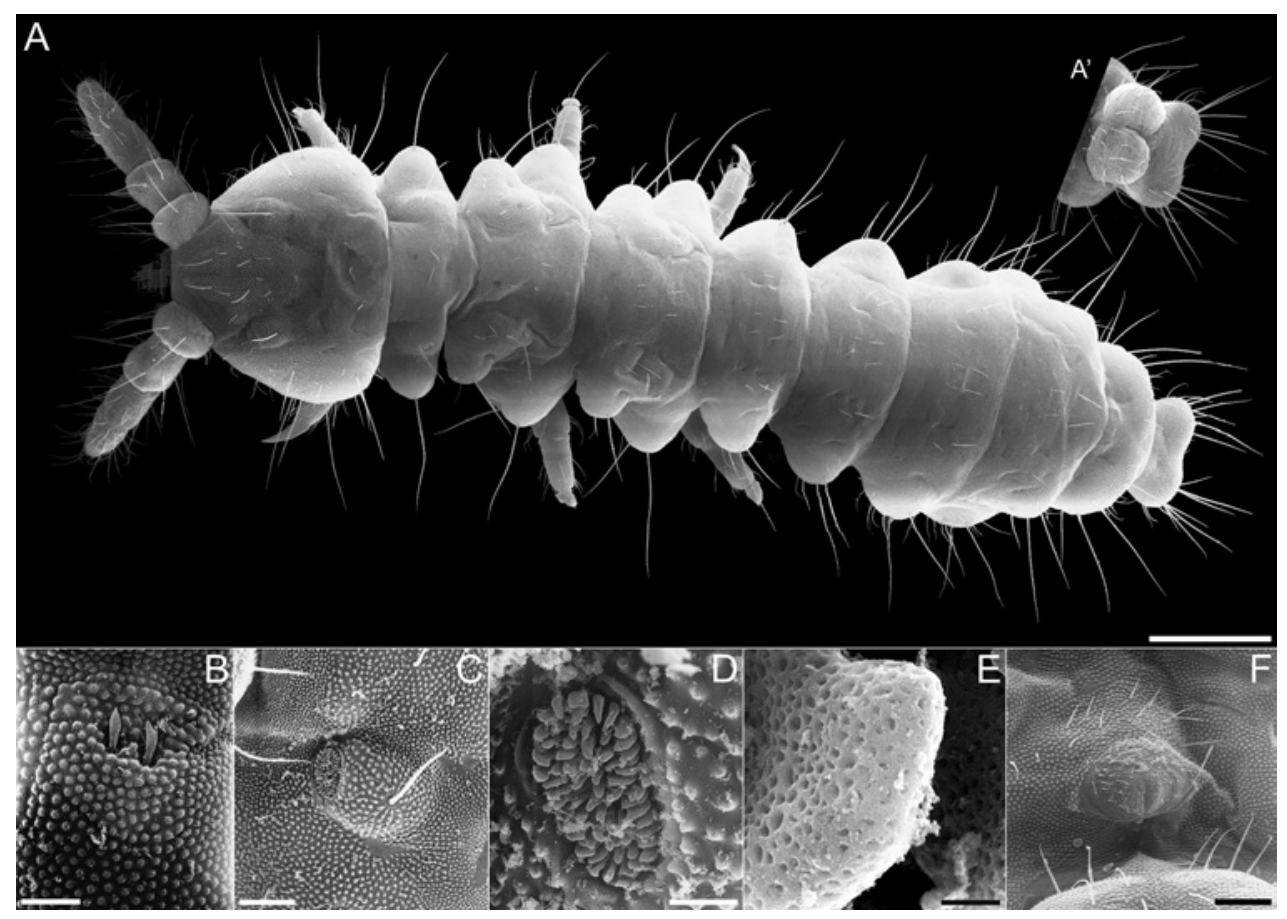

Figure 11. Anurida stereoodorata n. sp. SEM microphotographs. (A) Dorsal habitus (A', ventral Abd tip). (B) Sensory pegs of sensory organ of antennal segment III (scale bar: $20 \mu \mathrm{m})$. (C-D) PAO (bars: 70 and $20 \mu \mathrm{m}$ respectively). (E) Detail of a PAO vesicle, showing perforations (scale bar: $1 \mu \mathrm{m}$ ). (F) Male genital plate (scale bar: $60 \mu \mathrm{m}$ ).

Formula of 'sensory' chaetae $s$ per half tergum: 022/11111. Ms on Th II present, absent on Th III. Ventral chaetotaxy as in a Figure 10E. Ventral tube with $3+3$ chaetae (Figure 10E). Male genital plate in Figure 11F. Tibiotarsi I, II and III with 19, 19 and 18 chaetae, respectively (Figure 10B-C).

\section{Discussion}

Bellinger et al. (1996-2011) defined Pseudachorutinae as Collembola Neanuridae with: 1) mandible present without molar plate; 2) with or without furca (if present could be reduced to one or two knobs with chaetae); 3) sensillar chaetotaxy of Ant IV with fewer or more than 8 sensilla, never with 8; 4) without ms; 5) Abd VI usually not bilobed or truncated (nevertheless some species have this segment more or less truncate); 6) body without finger-like projections; 7) head and first thoracic segment dorsally separated. The triangular head of the maxilla separates it from Friesinae.

Deharveng (2004) hypothesized that Pseudachorutinae was para- or polyphyletic.

Anurida stereoodorata n. sp. could be considered as belonging to a new genus on the basis of the unique PAO and bilobed Abd VI. All other Anurida spp. have the PAO tubercles arranged in a circle or ellipse, and none has a bilobed Abd VI. 


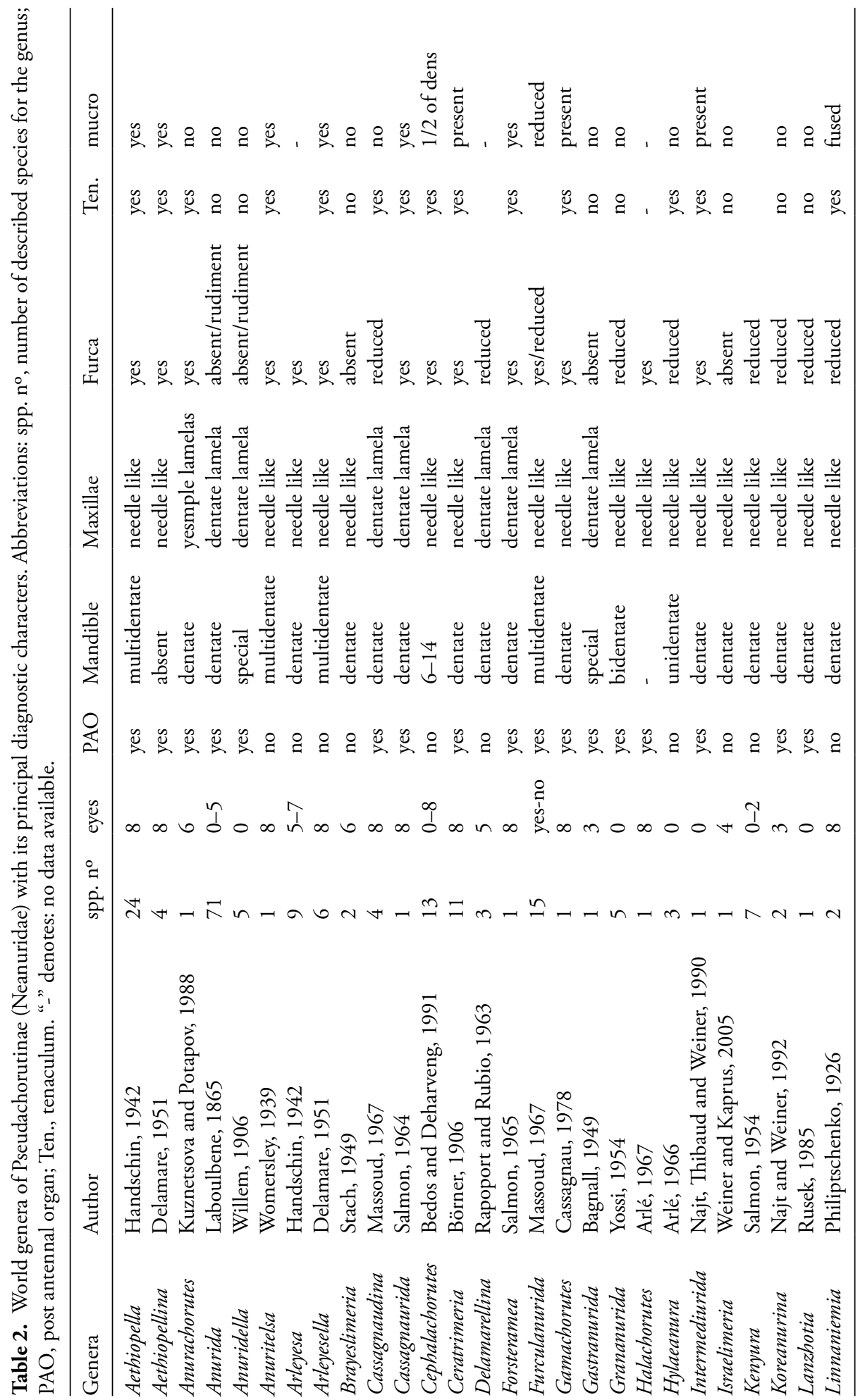




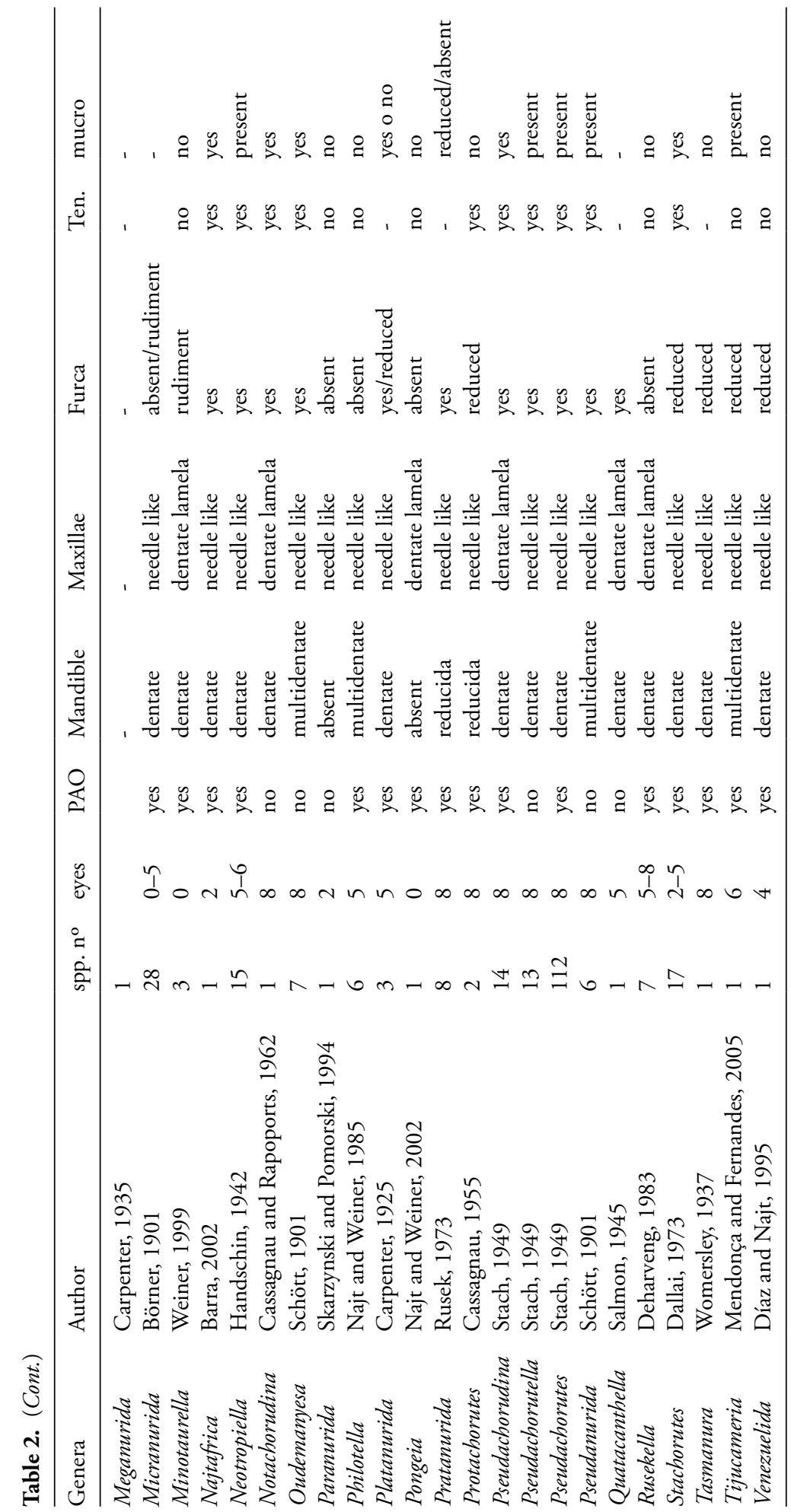




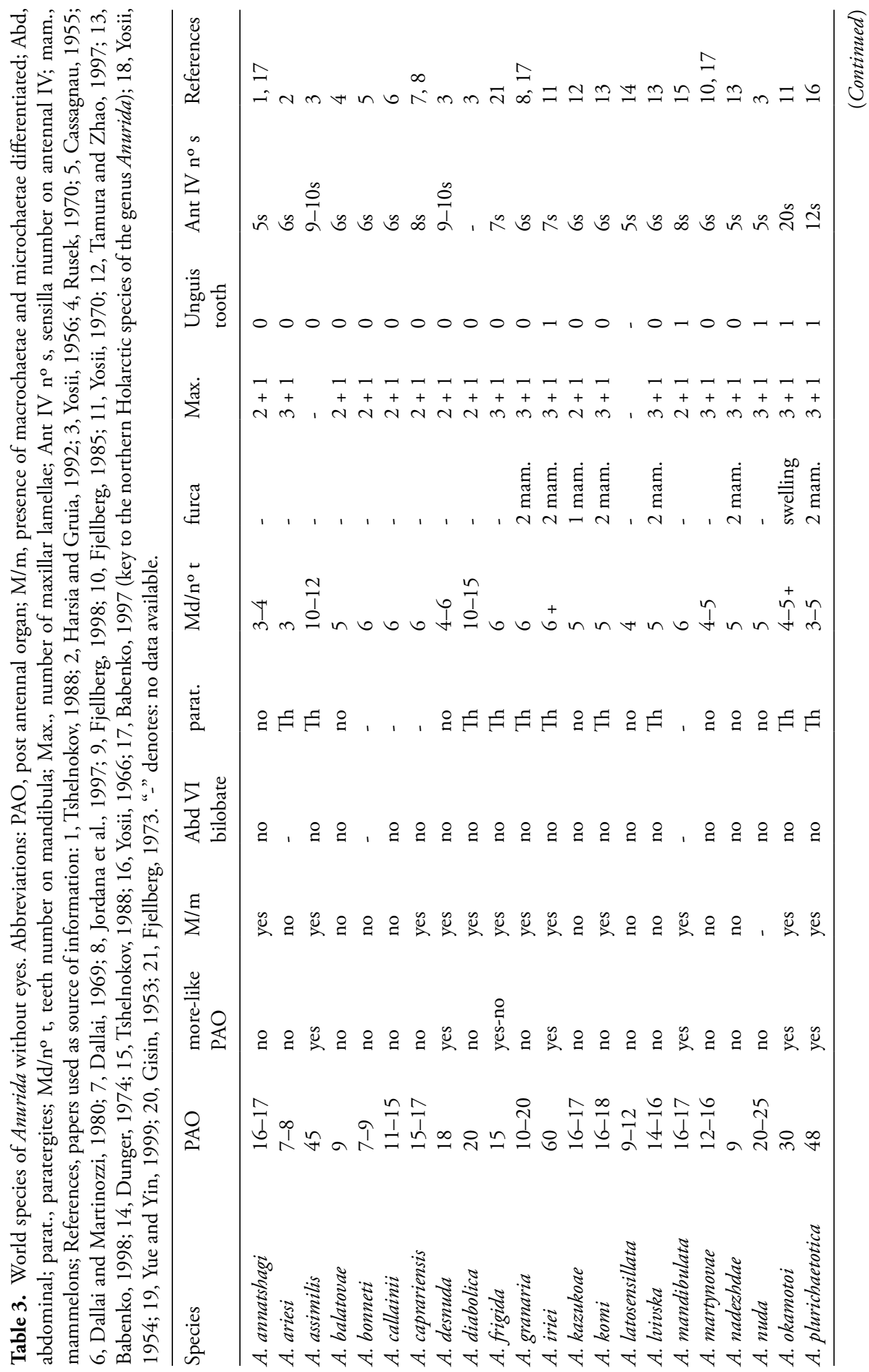




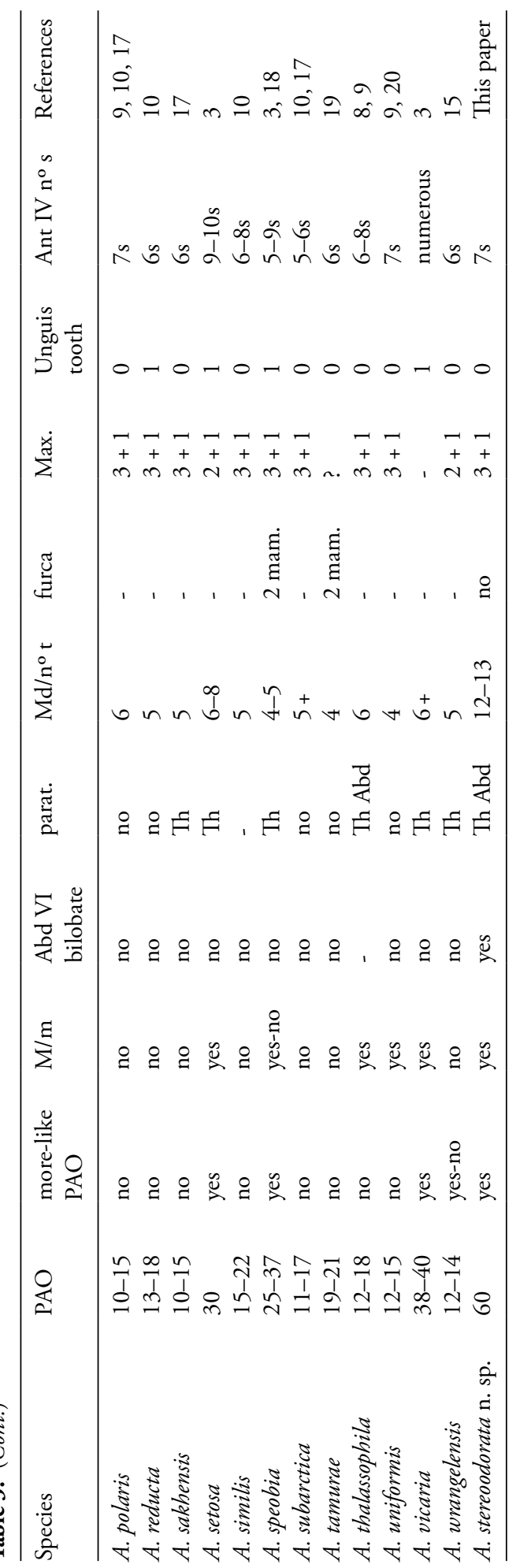


Thirty-three genera of Pseudachorutinae have the PAO present, but only 9 have some species without eyes (Table 2): Furculanurida Massoud, 1967, Grananurida Yosii, 1954, Intermediurida Najt, Thibaud and Weiner, 1990, Lanzhotia Rusek, 1985 and Micranurida Börner, 1901 have needle-like maxilla; Anurida Laboulbene, 1865 (71 spp.), Anuridella Willem, 1906 (5 spp.), Minotaurella Weiner, 1999 (1 sp.) and Pongeia Najt and Weiner, 2002 (1 sp.) have dentate or fringed maxillary lamellae. Anuridella has a unique form of mandible not present in the new species, Pongeia lacks mandibles, and Minotaurella has a tuberculate body.

Of the 71 described species of Anurida, 35 species lack eyes (Table 3). The PAO is roundish or oval, with vesicles in a single line, and occasionally with some vesicles in the interior part of the external line (morel-like form). Ten species share this characteristic of the PAO (not its dome shaped), and between them, only two species share with the new species the absence of tooth on the inner edge of the unguis: $A$. assimilis Yosii, 1956 and A. desnuda Yosii, 1956. Anurida assimilis has 45 vesicles in the PAO and $A$. desnuda has 18, while the new species has about 60. In the new species Abd VI is clearly bilobed and Ant IV has 7 sensilla, while the other two species have a rounded Abd VI and 9-10 sensilla on Ant IV. The other species with internal vesicles on an elliptic PAO are: A. wrangelensis Tshelnokov, 1988 and A. frigida Fjellberg, 1973; each of these species has $12-15$ vesicles in PAO and Abd VI is entire.

\section{Key to the world species of Anurida without eyes}

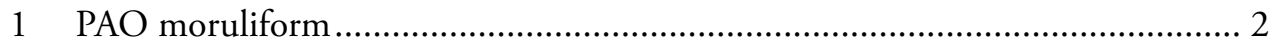

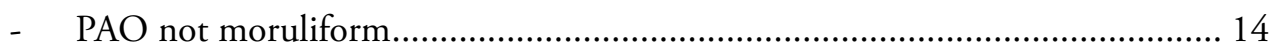

2 Macrochaeta and microchaeta differentiated ................................................... 4

- Macrochaeta and microchaeta not differentiated.................................................. 3

3 PAO with 25-37 vesicles................................. speobia Yosii, 1954 (Japan, cave)

- PAO with $12-14$ vesicles A. wrangelensis Tshelnokov, 1988 (Wrangel Isl. Arctic, Russia, soil)

4 More than 10 teeth on the mandible ............................................................. 5

- Fewer than 10 teeth on the mandible ................................................................ 6

5 Abd VI bilobed, PAO with 60 vesicles.......A. stereoodorata n. sp. (Abkhazia, cave)

- Abd VI not bilobed, PAO with 45 vesicles. A. assimilis Yoshii, 1956 (Japan, cave)

6 Unguis without internal tooth ...................................................................... 7

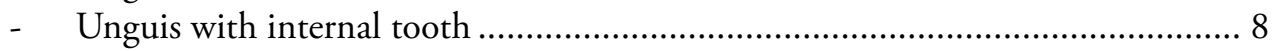

7 Th with paratergites, Ant IV with 7 sensilla

A. frigida Fjellberg, 1973 (Sweden, under moss)

- Th without paratergites, Ant IV with 9-10 sensilla.. A. desnuda Yosii, 1956 (Japan, cave)

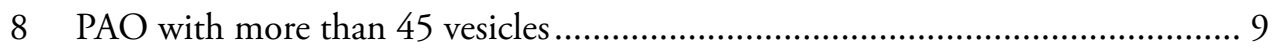

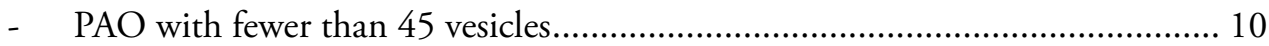


9 Ant IV with 7 sensilla, PAO with 60 vesicles A. iriei Yosii, 1970 (Japan, cave)

- Ant IV with 12 sensilla, PAO with 48 vesicles A. plurichaetotica Yosii, 1966 (South Korea, cave)

10 PAO with fewer than 20 vesicles

A. mandibulata Tshelnokov, 1988 (Magadan, Russia, tundra)

- PAO with more than 20 vesicles

11 PAO with 38-40 vesicles, Ant IV with numerous sensilla.

A. vicaria Yosii, 1956 (Japan, cave)

- $\quad$ PAO with fewer than 38 vesicles.

12 Maxilla with $2+1$ lamellae, Ant IV with 9-10 sensilla......

A. setosa Yosii, 1956 (Japan, cave?)

- Maxilla with 3 + 1 lamellae.

13 Ant IV with 5-9 sensilla .A. speobia Yosii, 1954 (Japan, cave)

- Ant IV with 20 sensilla A. okamotoi Yosii, 1970 (Japan, cave)

14 Mandible with 10-15 teeth. A. diabolica Yosii, 1956 (Japan, cave)

- Mandible with fewer than 10 teeth 15

15 Mandible with 6 teeth..... 16

- Mandible with fewer than 6 teeth 22

16 With macrocheatae and microchaetae differentiated .................................. 17

- Macrocheatae and microchaetae not differentiated ........................................ 20

17 Maxilla with $2+1$ lamellae................... caprariensis Dallai, 1969 (Europe, soil)

- Maxilla with $3+1$ lamellae.

18 Paratergites on Th and Abd

..A. thalassophila (Bagnall, 1939) Stach, 1949 (Europe, soil near sea shore)

- Paratergites only on Th

19 Ant IV with 6 sensilla....

A. granaria (Nicolet, 1847) Tullberg, 1869 (Holarctica and Australia)

- $\quad$ Ant IV with 7 sensilla A. frigida Fjellberg, 1973 (Sweden, under moss)

20 PAO with 7-9 vesicles A. bonneti Cassagnau, 1955 (France, soil)

- PAO with 10 or more vesicles

21 Maxilla with $2+1$ lamellae, Ant IV with 6 sensilla.

.A. callainii Dallai and Martinozzi, 1980 (Italy, soil)

- Maxilla with $3+1$ lamellae, Ant IV with 7 sensilla. A. polaris (Hammer, 1954) (Arctic)

22 Th with paratergites 23

- Th without paratergites 
23 Maxilla with $2+1$ lamellae.

A. wrangelensis Tshelnokov, 1988 (Wrangel Isl. Arctic, Russia, Soil) Maxilla with $3+1$ lamellae.

$24 \mathrm{PAO}$ with 7-8 vesicles A. ariesi Harsia and Gruia, 1992 (Romania)

$\mathrm{PAO}$ with more than 10 vesicles.

25 Furca reduced to 2 mamelons... 26

- Without furca. A. sakhensis Babenko, 1997 (Yakutia, Russia, soil)

26 With macrochaetae and microchaetae differentiated....

A. komi Babenko, 1998 (Russia, soil)

- Macrochaetae and microchaetae not differentiated A. lvivska Babenko, 1998 (Ukraine, mossy soil)

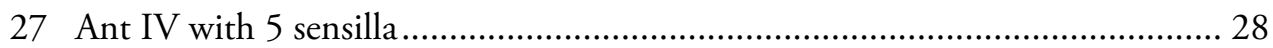

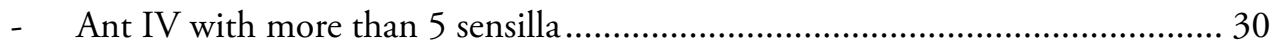

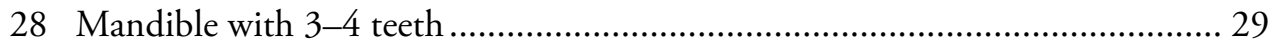

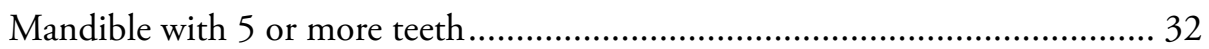

29 With macrochaetae and microchaetae differenciated.

A. annatshagi Tshelnokov, 1988 (Russia, soil tundra)

- Macrochaetae and microchaetae not differenciated.

A. latosensillata Dunger, 1974 (Germany, soil)

30 PAO with 9 vesicles............ nadezhdae Babenko, 1998 (Taymir, Russia, soil)

- $\quad$ PAO with more than 9 vesicles ................................................................... 31

31 PAO with 11-17 vesicles.................. A. subarctica Fjellberg, 1985 (Alaska, U.S.A)

- PAO with 20-25 vesicles................................. A. nuda Yosii, 1956 (Japan, cave)

32 Mandible with 4 teeth .................................................................................... 33

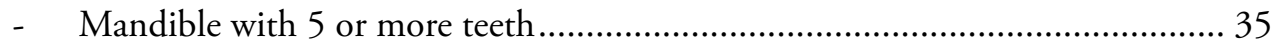

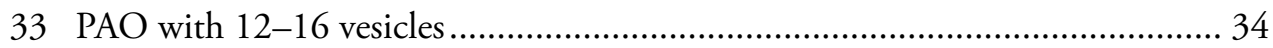

- PAO with 19-21 vesicles .................... tamurae Yue and Yin, 1999 (China, soil)

34 Ant IV with 6 sensilla.............. martynovae Fjellberg, 1985 (Alaska and Canada) - Ant IV with more than 5 sensilla............. A. uniformis Gisin, 1953 (Europe, soil)

35 PAO with 9 vesicles........... A. balatovae Rusek, 1970 (Czhechia and Poland, soil) PAO with more than 9 vesicles .................................................................... 36

36 Unguis with internal tooth .............................. A. reducta Fjellberg, 1985 (Arctic)

- Unguis without internal tooth ......................................................................... 37

37 Maxilla with $2+1$ lamellae........A. kazukoae Tamura and Zhao, 1997 (China, soil) Maxilla with 3 + 1 lamellae........................................................................... 38 
38 With asymmetric vesicles A. subarctica Fjellberg, 1985 (Alaska, U.S.A)

- PAO rounded or oval, with symmetric vesicles 39

39 Vesicles of PAO narrow or compressed

A. similis Fjellberg, 1985 (Alaska and USA, soil)

- PAO rounded and without compressed vesicles

.A. martynovae Fjellberg, 1985 (Alaska and Canada)

\section{Deuteraphorura kruberaensis Jordana and Baquero n. sp.}

(Figures 12-14)

\section{Type locality}

Krubera Cave (called too Voronya Cave or Voronja Cave), Arabika Massif, Gagrinsky Range of the Western Caucasus, Gagra district of Abkhazia (Ortobalagan).

\section{Type material}

Holotype (female) on slide, $-15 \mathrm{~m}$ from entrance ( $2420 \mathrm{~m}$ above sea level), pitfall trap, between 26.VII.2010 to 24.VIII.2010. Coordinates: lat $43.409722^{\circ}$, long $40.362222^{\circ}$ $\left(43^{\circ} 24^{\prime} 35.00^{\prime \prime} \mathrm{N}, 40^{\circ} 21^{\prime} 44.00^{\prime \prime} \mathrm{E}\right)$. CaveX Team leg. 2 paratypes (male and subadult) on slide, 2 paratypes on SEM stub and 16 paratypes in ethyl alcohol. Deposited in Museu de Valencia (Holotype and 10 Paratypes) and MZNA (10 Paratypes).

\section{Etymology}

The species name is derived from the name of the cave (Krubera) where the specimens were collected.

\section{Description}

Body length up to $2.2 \mathrm{~mm}$ (average 1.6, $\mathrm{n}=17$ ), cylindrical, with uniform cuticular granulation except for small areas on all tergites (Figure 12A, dotted line). Colour white in alcohol. Length of Ant I, II, III and IV as 50, 80, 70 and $150 \mu \mathrm{m}$. Ratio antennae/head diagonal $=0.72$. Antennal base well marked. Ant IV (Figure 12D) with subapical organite and $\mathrm{ms}$ at its base, in latero-external position; 30-40 thin chaetae like sensilla, not well distinguishable from chaetae, on the distal two third of Ant IV, in the opposite side of the antennal III sense organ. Antennal III sense organ with two sensory rods, two sensory ribbed clubs (Figure 12B') protected by five papillae and its respective five guard chaetae, and a ventral ms (Figure 12B). PAO consisting of 19-21 compound vesicles disposed in two parallel rows (Figure 12C). Labrum with 4/142 chaetae (Figure 13A). Submentum with $4+4$ chaetae, basolateral field (mentum) with 5 chaetae; outer maxillary lobe with one basal chaeta and two sublobal hairs. Labial papillae of A type (according to Fjellberg 1999), with six proximal chaetae; labial papillae A, B, C, D, E with 1, 4, 0, 3, 3 guard chaetae respectively (Figure 13B). Mandible with four apical teeth, only the basal slightly different in both mandibles (Figure 13C); 


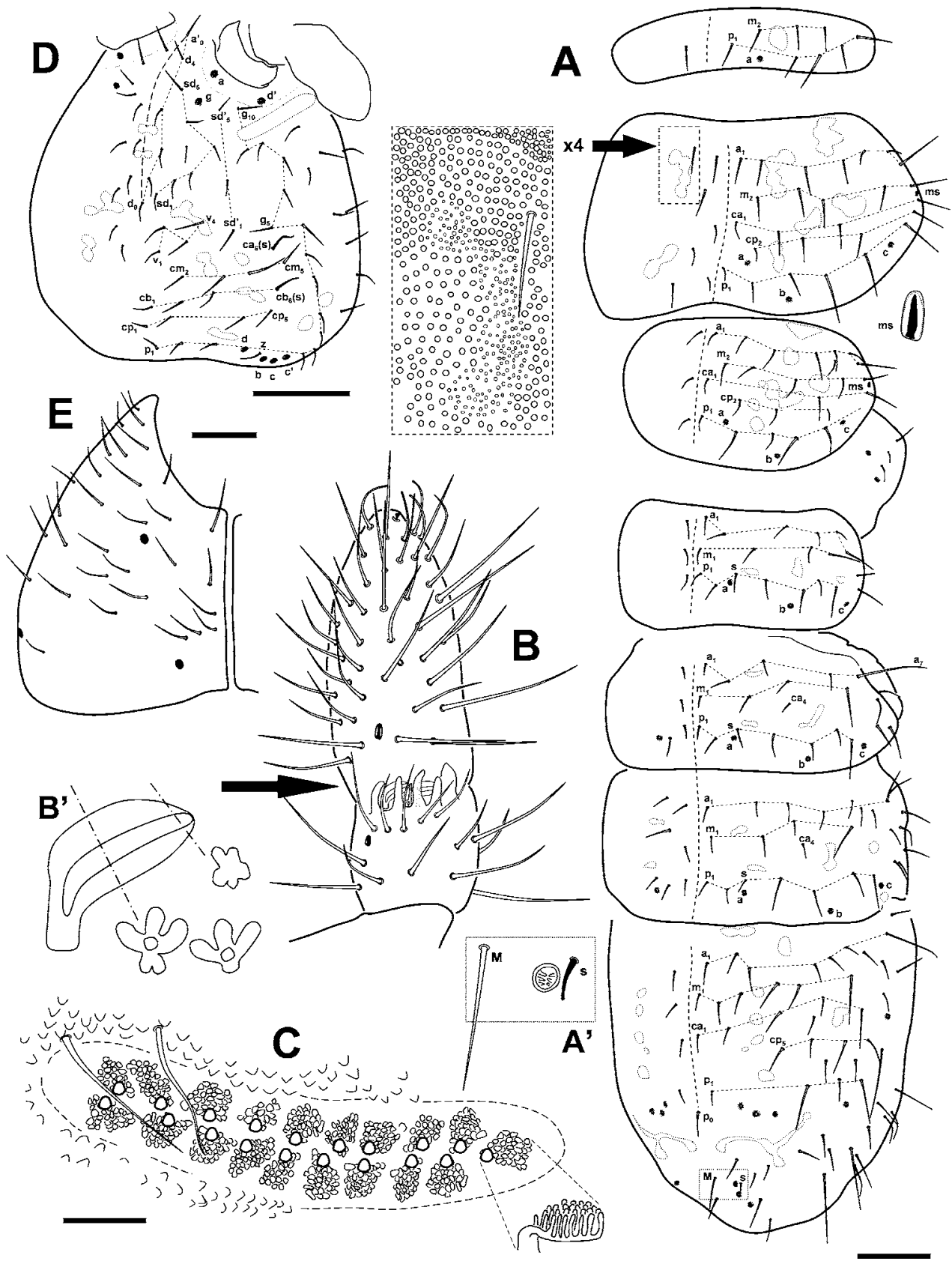

Figure 12. Deuteraphorura kruberaensis n. sp. (A) Dorsal chaetotaxy of the thoracic and abdominal tergites (A', detail of chaeta $\mathbf{M}$ and chaeta $\mathbf{s}$ of the tergite V) (scale bar: $100 \mu \mathrm{m})$. (B) Ant III-IV (B', detail of the sensory clubs with two sections). (C) PAO (postantennal organ) (scale bar: $20 \mu \mathrm{m}$ ). (D) Dorsal head chaetotaxy (scale bar: $90 \mu \mathrm{m}$ ). (E) Ventral head chaetotaxy (scale bar: $60 \mu \mathrm{m}$ ). 

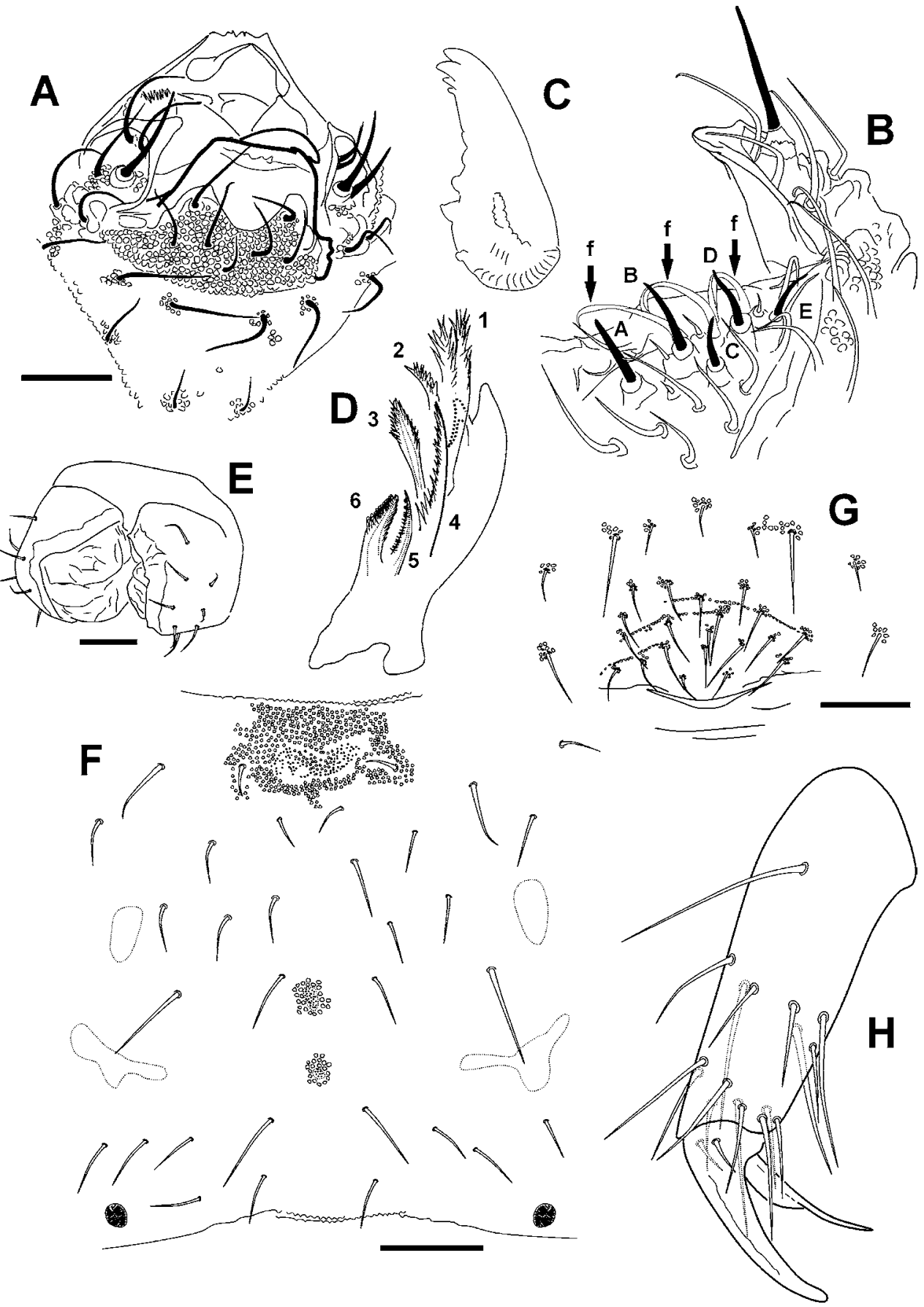

Figure 13. Deuteraphorura kruberaensis $\mathrm{n}$. sp. (A) Labrum chaetotaxy (scale bar: $40 \mu \mathrm{m}$ ). (B) Labial palp chaetotaxy (labial papillae A, B, C, D and E) and outer maxillary lobe (f: flattened chaetae). (C) Mandible. (D) Maxilla. (E) Ventral tube (scale bar: $40 \mu \mathrm{m}$ ) (F) Ventral view of Abd IV, with the vestigial furca at the top (scale bar: $50 \mu \mathrm{m}$ ). (G) Detail of the female genital aperture (scale bar: $40 \mu \mathrm{m}$ ). (H) Tibiotarsus, unguis and unguiculus of leg III. 


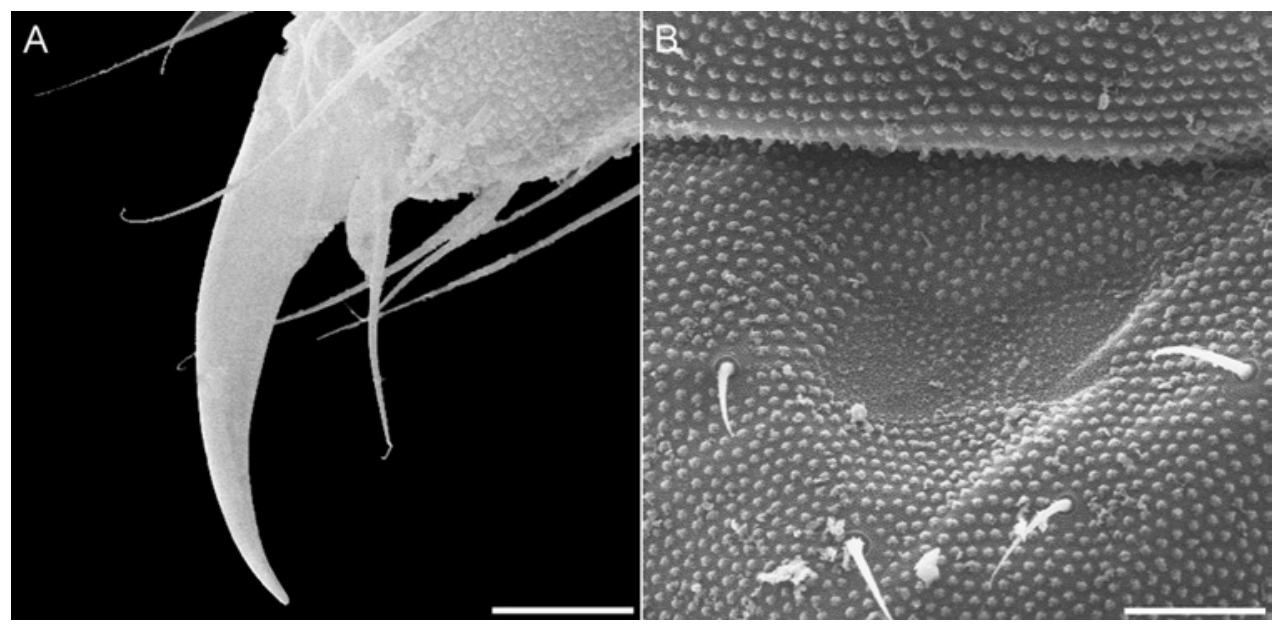

Figure 14. Deuteraphorura kruberaensis n. sp. SEM microphotographs. (A) Unguis and unguiculus of leg III. (B) Area of vestigial furca (bar, A and B: $20 \mu \mathrm{m}$ ).

Table 4. Deuteraphorura kruberaensis n. sp. head chaetotaxy. Abbreviations: m, microchaeta; M, macrochaeta; s, sensilla; z, chaeta z. "-" denotes: absence of chaeta.

\begin{tabular}{lllllllll}
\hline Chaeta number/serie & 0 & 1 & 2 & 3 & 4 & 5 & 6 & 7 \\
\hline $\mathrm{d}$ & $\mathrm{m}$ & $\mathrm{m}$ & $\mathrm{m}$ & $\mathrm{m}$ & $\mathrm{m}$ & - & - & - \\
$\mathrm{sd}$ & - & $\mathrm{m}$ & $\mathrm{m}$ & $\mathrm{m}$ & $\mathrm{m}$ & $\mathrm{M}$ & - & - \\
$\mathrm{sd}$ & - & $\mathrm{m}$ & $\mathrm{m}$ & - & - & $\mathrm{m}$ & - & - \\
$\mathrm{v}$ & - & $\mathrm{m}$ & $\mathrm{M}$ & $\mathrm{m}$ & $\mathrm{M}$ & - & - & - \\
$\mathrm{ca}$ & - & - & - & - & - & - & $\mathrm{s}$ & - \\
$\mathrm{cm}$ & - & - & $\mathrm{m}$ & $\mathrm{m}$ & $\mathrm{M}$ & $\mathrm{m}$ & - & - \\
$\mathrm{cb}$ & - & $\mathrm{m}$ & $\mathrm{m}$ & $\mathrm{m}$ & - & - & $\mathrm{s}$ & - \\
$\mathrm{cp}$ & - & $\mathrm{m}$ & $\mathrm{m}$ & - & $\mathrm{m}$ & $\mathrm{m}$ & - & - \\
$\mathrm{p}$ & - & $\mathrm{m}$ & $\mathrm{m}$ & $\mathrm{m}$ & $\mathrm{z}$ & $\mathrm{m}$ & $\mathrm{m}$ & - \\
$\mathrm{g}$ & 11 chaetae, $\mathrm{g}_{5}$ as & & & & & & & \\
\hline
\end{tabular}

maxillary head as in Figure 13D. Unguis without inner or outer teeth; unguiculus with basal lamella (Figures 13H, 14A). Ventral tube with $8+8$ apical chaetae, without basal chaetae (Figure 13E). Furca reduced to a finely granulated area with $1+1$ small chaetae backward (Figures 13F and 14B). Typical dorsal pseudocellar formula 34/133/33353, but frequently variable, specially on Abd IV (3-5 pseudocelli), common disposition on Abd IV $3+1+1$ from dorsal axis to lateral, sometimes $1+0+2$. Ventral pseudocellar formula 3/011/31110. Subcoxae 1 of all legs each with 2 pseudocelli. 
Table 5. Deuteraphorura kruberaensis n. sp. dorsal thoracic chaetotaxy. Abbreviations: m, microchaeta; M, macrochaeta; s, sensilla; ms, microsensilla. "-" denotes: absence of chaeta.

\begin{tabular}{llllllll}
\hline Chaeta number/serie & 1 & 2 & 3 & 4 & 5 & 6 & 7 \\
\hline Th I & - & $\mathrm{m}$ & - & $\mathrm{m}$ & $\mathrm{m}$ & - & - \\
$\mathrm{m}$ & $\mathrm{m}$ & - & - & $\mathrm{m}$ & $\mathrm{m}$ & $\mathrm{m}$ & $\mathrm{M}$ \\
$\mathrm{p}$ & & & & & & & \\
\hline Th II & $\mathrm{m}$ & $\mathrm{m}$ & $\mathrm{m}$ & $\mathrm{m}$ & $\mathrm{m}$ & $\mathrm{m}$ & $\mathrm{M}$ \\
$\mathrm{a}$ & - & $\mathrm{m}$ & $\mathrm{m}$ & - & $\mathrm{m}$ & $\mathrm{m}$ & $\mathrm{M}(+\mathrm{ms})$ \\
$\mathrm{m}$ & $\mathrm{m}$ & - & $\mathrm{m}$ & - & $\mathrm{m}$ & - & $\mathrm{M}$ \\
$\mathrm{ca}$ & - & $\mathrm{m}$ & - & $\mathrm{m}$ & - & $\mathrm{m}$ & $\mathrm{M}$ \\
$\mathrm{cp}$ & $\mathrm{m}$ & - & $\mathrm{M}$ & $\mathrm{m}$ & $\mathrm{M}$ & $\mathrm{M}$ & $\mathrm{M}$ \\
$\mathrm{p}$ & & & & & & & \\
\hline Th III & $\mathrm{m}$ & $\mathrm{m}$ & $\mathrm{m}$ & $\mathrm{m}$ & $\mathrm{m}$ & $\mathrm{m}$ & $\mathrm{M}$ \\
$\mathrm{a}$ & - & $\mathrm{m}$ & $\mathrm{m}$ & - & $\mathrm{m}$ & $\mathrm{m}$ & $\mathrm{M}$ \\
$\mathrm{m}$ & $\mathrm{m}$ & - & - & - & $\mathrm{m}$ & - & $\mathrm{M}$ \\
$\mathrm{ca}$ & - & $\mathrm{m}$ & - & $\mathrm{m}$ & - & $\mathrm{m}$ & - \\
$\mathrm{cp}$ & $\mathrm{m}$ & - & $\mathrm{m}$ & $\mathrm{m}$ & $\mathrm{M}$ & $\mathrm{M}$ & - \\
$\mathrm{p}$ & & & & & & & \\
\hline
\end{tabular}

Table 6. Deuteraphorura kruberaensis $\mathrm{n}$. sp. dorsal abdominal chaetotaxy. Abbreviations: $\mathrm{m}$, microchaeta; M, macrochaeta; s, sensilla; z, chaeta z. "-” denotes: absence of chaeta.

\begin{tabular}{lllllllll}
\hline Chaeta number/serie & 1 & 2 & 3 & 4 & 5 & 5 & 6 & 7 \\
\hline Abd I-III & $\mathrm{m}$ & $\mathrm{mm}-$ & - & $\mathrm{m}$ & $\mathrm{m}-\mathrm{m}$ & - & $\mathrm{m}$ & $\mathrm{M}$ \\
$\mathrm{a}$ & $\mathrm{m}$ & - & - & $\mathrm{m}$ & $\mathrm{m}$ & - & - & $\mathrm{M}$ \\
$\mathrm{m}$ & - & - & - & $-\mathrm{mm}$ & - & - & - & - \\
$\mathrm{ca}$ & $\mathrm{m}$ & $\mathrm{m}$ & $\mathrm{s}$ & $\mathrm{m}$ & $\mathrm{m}$ & - & $\mathrm{m}$ & $\mathrm{M}$ \\
$\mathrm{p}$ & & & & & & & & \\
\hline Abd IV & $\mathrm{m}$ & $\mathrm{m}$ & $\mathrm{m}$ & - & $\mathrm{m}$ & - & $\mathrm{m}$ & - \\
$\mathrm{a}$ & $\mathrm{m}$ & $\mathrm{m}$ & $\mathrm{m}$ & $\mathrm{m}$ & $\mathrm{m}$ & - & - & $\mathrm{M}$ \\
$\mathrm{m}$ & $\mathrm{m}$ & $\mathrm{m}$ & - & - & $\mathrm{m}$ & - & $\mathrm{m}$ & $\mathrm{M}$ \\
$\mathrm{ca}$ & - & - & - & - & $\mathrm{m}$ & $\mathrm{m}$ & $\mathrm{M}$ & $\mathrm{M}$ \\
$\mathrm{cp}$ & $\mathrm{m}$ & - & - & - & - & - & $\mathrm{m}$ & $\mathrm{M}$ \\
$\mathrm{p}$ & & & & & & & &
\end{tabular}

\section{Chaetotaxy}

Lateral ms on Th II and III. Distribution of dorsal chaetae as in Figure 12A, 12D and Tables 4-6; asymmetries are common. Chaeta $\mathrm{p}_{0}$ present on Abd IV and VI. Ratio chaetae M/s = 2.7 on Abd V; longest macrochaetae on Abd VI: $110 \mu \mathrm{m}$. Without chaetae on ventral thoracic sternites; ventral chaetotaxy of head as in Figures 12D (dorsal) and 12E (ventral). Female genital area with 20 chaetae (Figure 13G).

Tibiotarsi I, II, and III with 18, 18 and 17 chaetae respectively; distal whorl with 9 chaetae. 


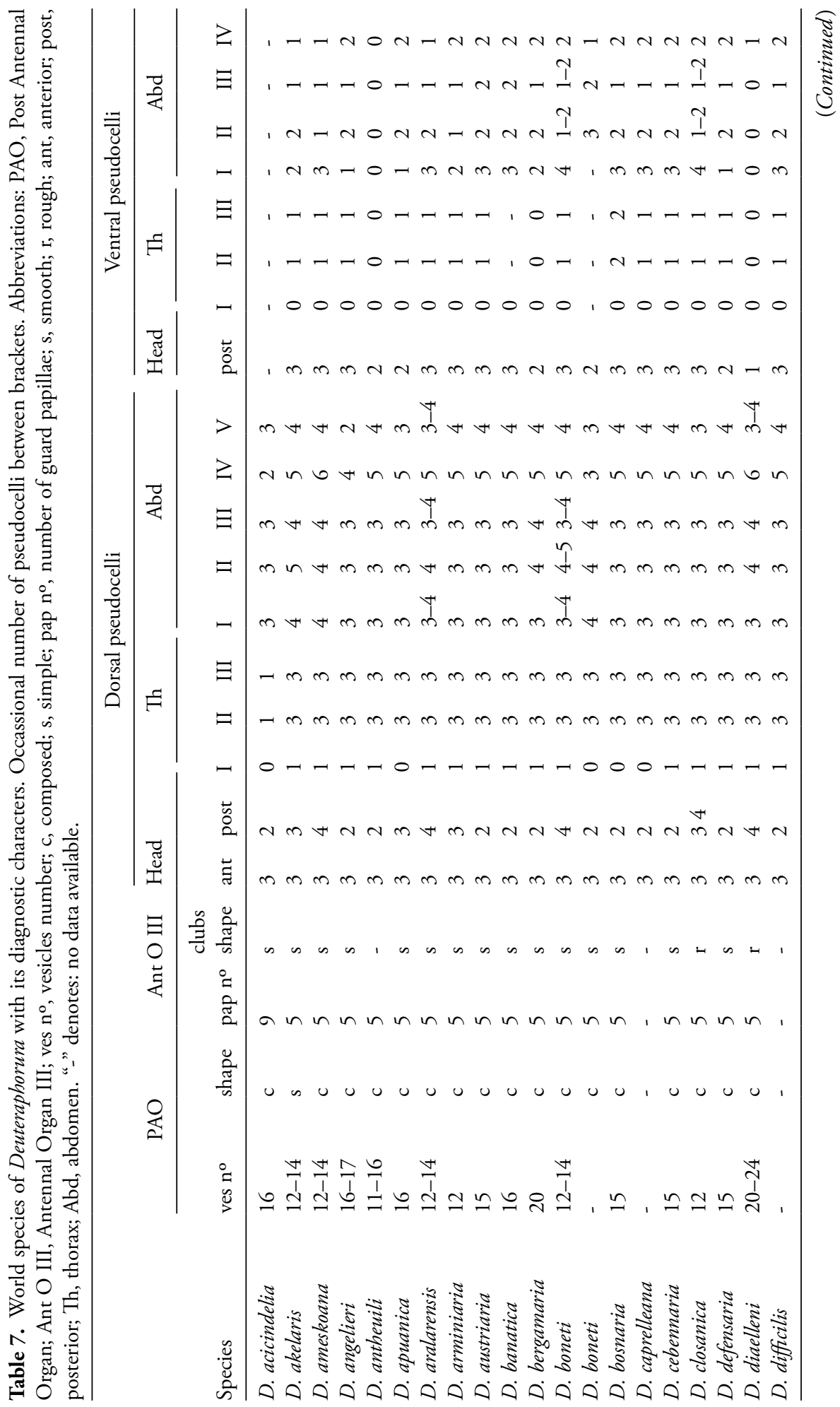




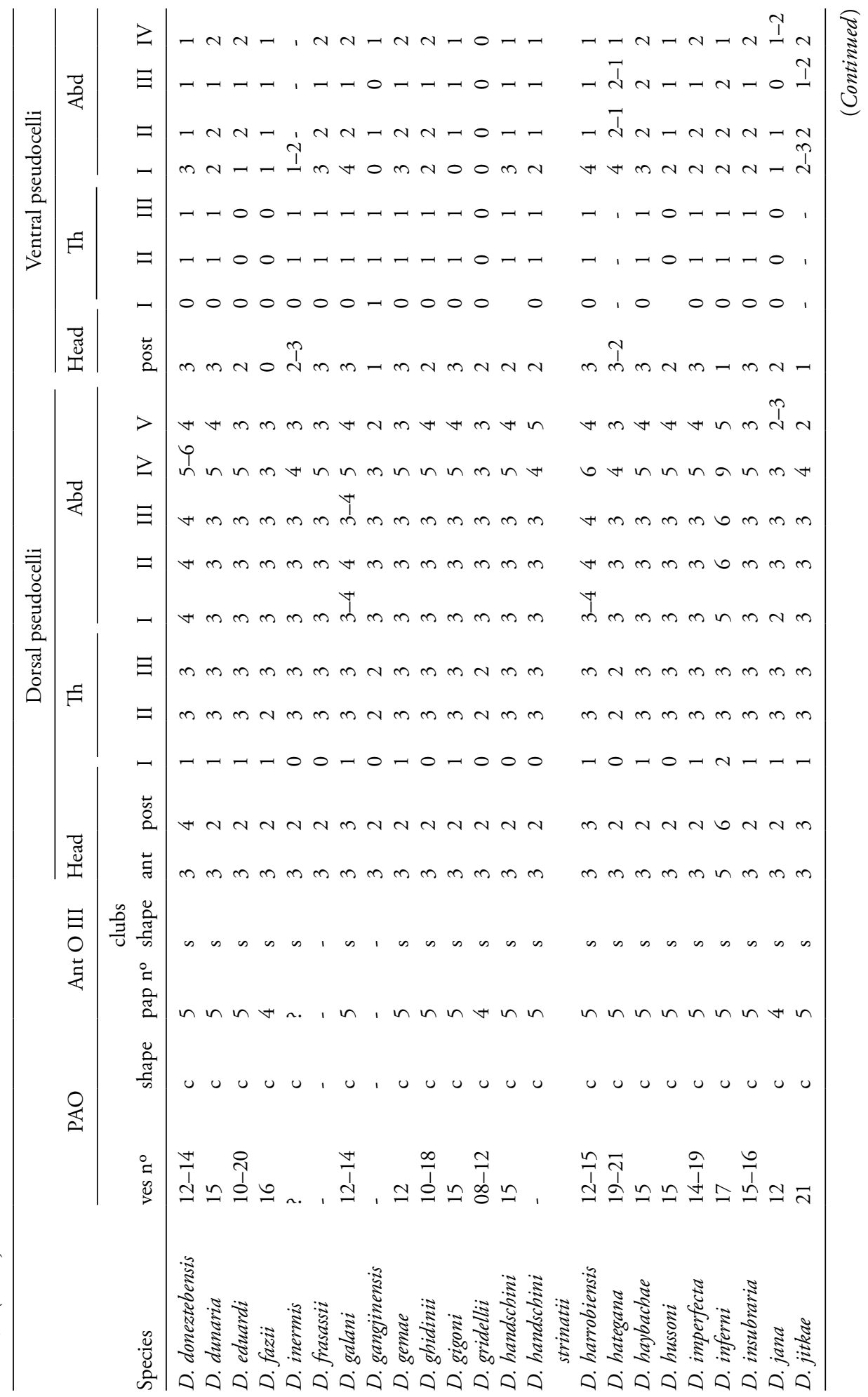




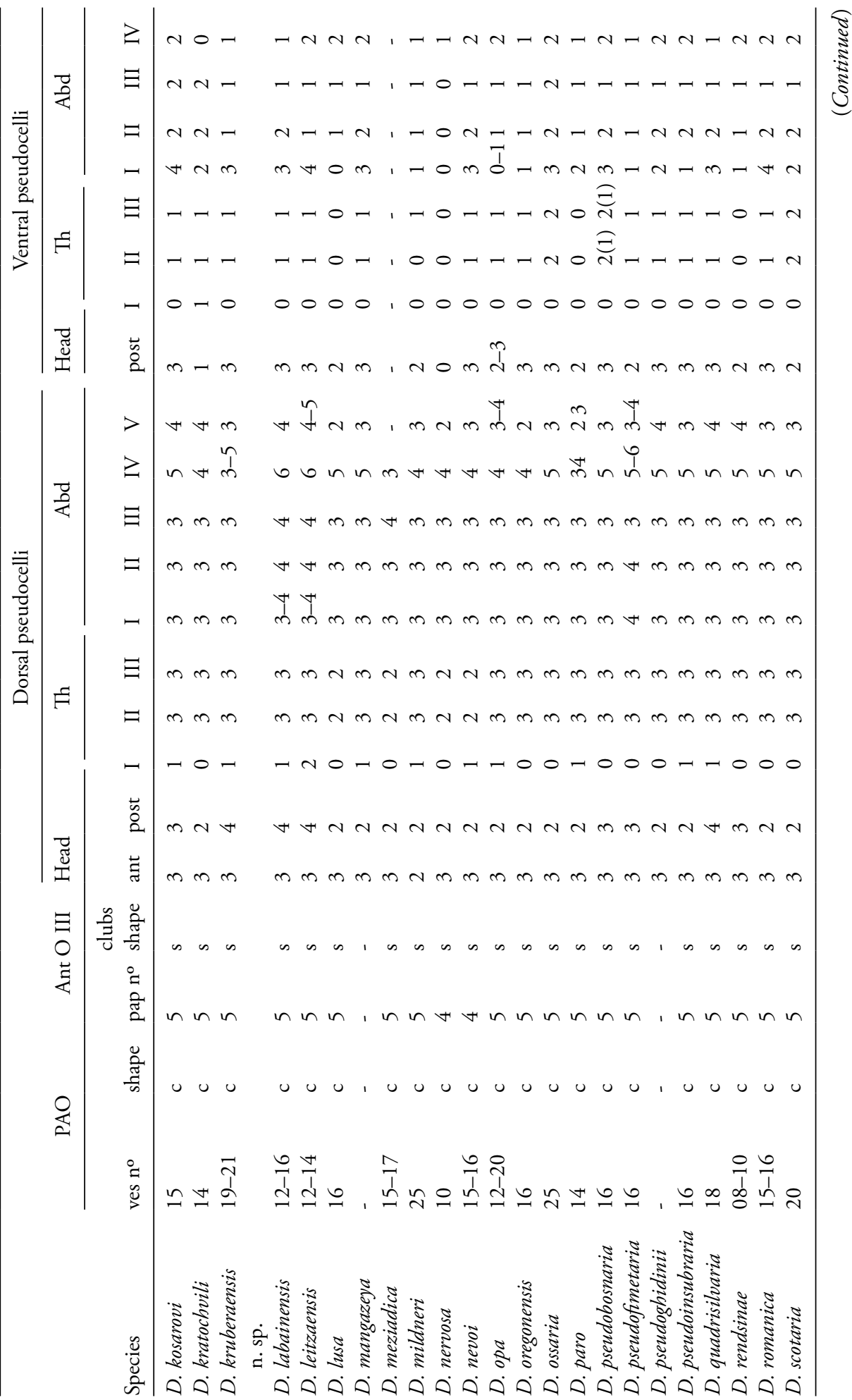




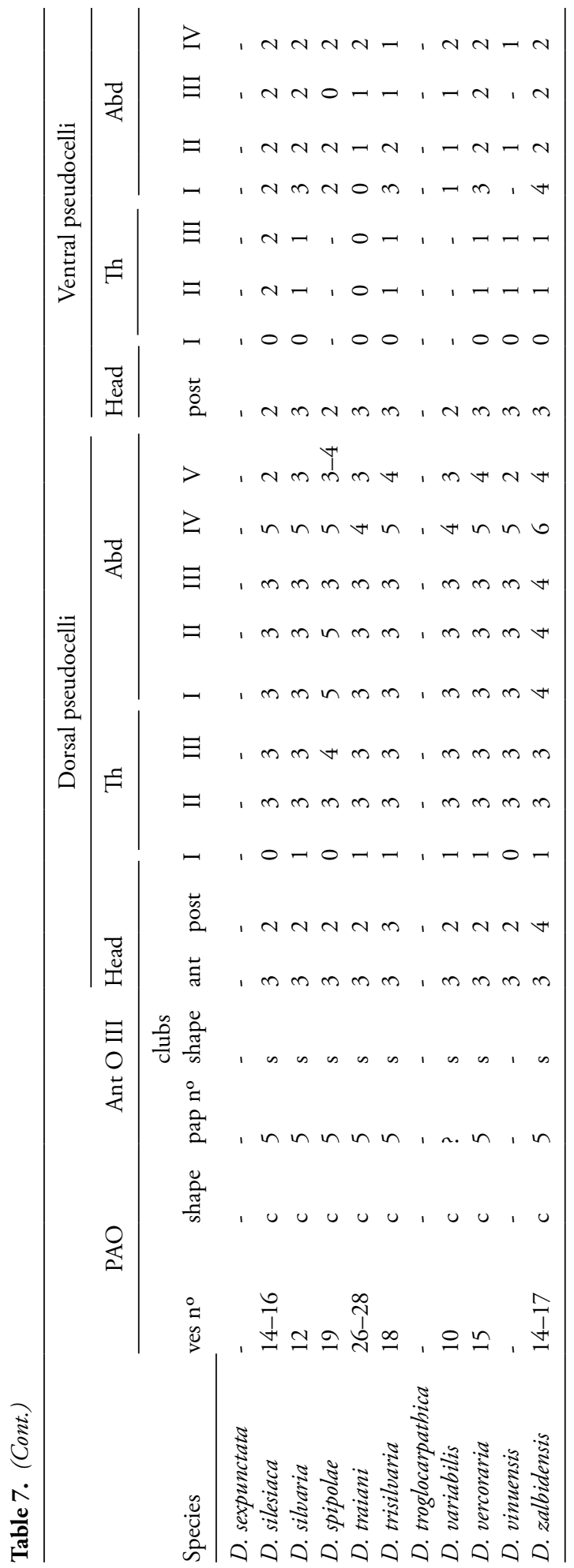




\section{Discussion}

The characters used by Weiner (1996) and Pomorski (1998) in the diagnosis of the genus Deuteraphorura are: PAO with compound vesicles, sensory clubs in Ant III organ ovoid, curved (or bent), smooth with one or two ribs in the middle, sensilla on Ant IV sligtly marked, two stout sensilla present, and microsensillum (ms) at 1/4 the length of the segment, base of antenna well marked, posterior pseudocelli on the head present, Th I with $1+1$ or $0+0$ pseudocelli, tergites from Th II to Abd III with few pseudocelli, Abd IV and V with 4-5+4-5 and $3+3$ pseudocelli respectively, sensilla(s) on the body differentiated, rather well marked on the head $(2+2)$ and Abd V and VI, chaeta $\mathrm{d}_{0}$ on the head present, Abd VI with two rows of chaetae, $\mathrm{a}_{0}$ present, anal spines absent, furcal rudiment with finelly granulated area and four small chaetae posteriorly, two manubrial row of chaetae present. The new species has all these characters except the last two: furcal rudiment with finely granulated area and two small chaetae posteriorly, relatively backward, and more than two manubrial row of chaetae.

To ascertain the nature of the latter two characters, we studied the type series of D. ameskoana (Beruete et al., 2001), D. aralarensis (Beruete et al., 2001), D. boneti Gisin, 1953 (Beruete et al., 2001), D. doneztebensis (Beruete et al., 2001), D. labainensis (Beruete et al., 2001), D. leitzaensis (Beruete et al., 2001) and D. zalbidensis (Beruete et al., 2001). In those, we observed considerable intraspecific variation, including four small chaetae in a row, four small chaetae in an asymmetric row, four small chaetae in a trapezoidal disposition (with the lesser wide backward), two (in some cases three) small chaetae. In all these species, there are three or four manubrial rows of chaetae. Therefore, we consider that these small differences do not justify erecting a new genus. Also, we have avoided those characters in the key to the species of Deuteraphorura.

Deuteraphorura contains 77 described species (Table 7). This new species belongs to a group of 10 species with four posterior dorsal cephalic pseudocelli; these species occur in European caves, mostly in Spain (Gisin, 1953, 1962; Gruia, 1965; Neuertz and Nosek, 1976 and Beruete et al, 2001): D. ameskoana, D. aralarensis, D. boneti, D. closanica (Gruia, 1965), D. diaelleni (Neuhertz and Nosek, 1976), D. doneztebensis. D. labainensis, D. leitzaensis, D. quadrisilvaria (Gisin, 1962) and D. zalbidensis. They can be distinguished from $D$. kruberaensis $\mathrm{n}$. sp. by the following characteristics: $D$. leitzaensis has two pseudocelli on dorsal Th I; $D$. closanica and $D$. diaelleni has morellike (after Weiner, 1996) sensory clubs in antennal III sense organ; $D$. ameskoana, $D$. boneti, $D$. doneztebensis and D. zalbidensis have four pseudocelli on ventral abdominal tergite I, and $D$. aralarensis, $D$. lebainensis and $D$. quadrisilvaria have two ventral pseudocelli on abdominal sternite II.

\section{Key to the world species of Deuteraphorura}

1 Two posterior dorsal cephalic pseudocelli ....................................................... 2

- More than 2 posterior dorsal cephalic pseudocelli........................................... 52

22 pseudocelli on dorsal anterior part of the head. 
- $\quad 3$ pseudocelli on dorsal anterior part of the head................................................. 3

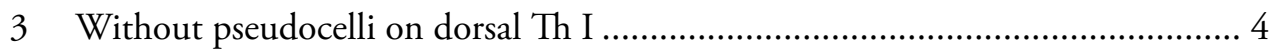

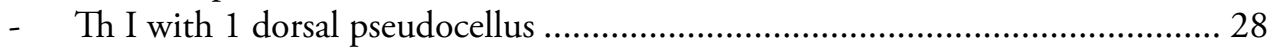

4 Th II-III with 1 dorsal pseudocellus

.D. acicindelia (Salmon, 1958) (New Zealand, cave)

- Th II-III with more than 1 dorsal pseudocellus ................................................. 5

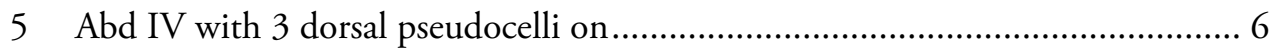

- Abd IV with more than 3 dorsal pseudocelli................................................... 8

6 Abd I-III with 4 dorsal pseudocelli ............. D. boneti (Gisin, 1953) (Spain, cave)

- Abd I-III with 3 dorsal pseudocelli .................................................................... 7

7 Formula of ventral pseudocelli 1/111/0101

D. gangjinensis (Lee and Kim, 1995) (South Korea, soil)

- Formula of ventral pseudocelli 2/000/0000 D. gridelli (Denis, 1938) (Italy, soil)

8 Abd IV with 4 dorsal pseudocelli .................................................................... 9

- Abd IV with 5 dorsal pseudocelli .................................................................. 15

9 Th II-III with 2 dorsal pseudocelli ........................................................... 10

- Th II-III with 3 dorsal pseudocelli .............................................................. 12

10 Ant III sensory organ with 4 papillae.

D. nervosa (Stach, 1954) (Europe, cave \& surface)

- Ant III sensory organ with 5 papillae................................................................ 11

11 PAO with 19-21 compound tubercles.

D. hategana (Gruia, 1971) (Romania, cave)

- PAO with 15-17 compound tubercles

D. meziadica (Gruia, 1972) (Romania, cave)

12 Abd V with 2 dorsal pseudocelli D. oregonensis (Denis, 1929) (USA, cave)

- Abd V with more than 2 dorsal pseudocelli

13 Abd V with 3 dorsal pseudocelli

D. inermis (Tullberg, 1869) Absolon, 1901 (Holarctic and Australia)

- $\quad$ Abd V with more than 3 dorsal pseudocelli ...................................................... 14

14 Abd V with 4 dorsal pseudocelli........... . kratochvili (Nosek, 1963) (Europe, cave)

- Abd V with 5 dorsal pseudocelli D. handschini strinatii Gisin, 1963 (Suitzerland, cave)

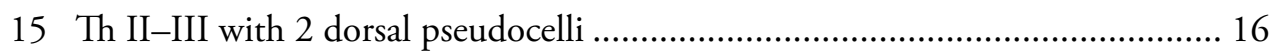

- Th II-III with 3-3 or 3-4 dorsal pseudocelli .................................................. 17 
16 Ventral formula $2 / 000 / 0112$

D. lusa (Christiansen and Bellinger, 1980) (USA and Canada, surface)

- Ventral formula 3/011/4212............. D. romanica (Gruia, 1965) (Romania, cave)

17 Th II-III with 3-3 dorsal pseudocelli

- ThII-IIIwith3-4dorsalpseudocelli.

D. spipolae Massera, 1949 (Italy, cave)

18 Abd V with 2 dorsal pseudocelli 19

- Abd V with more than 2 dorsal pseudocelli 20

19 Ventral formula of pseudocelli 2/022/2222

..D. silesiaca (Dunger, 1977) (Czechia, Poland and Hungary)

- Ventral formula of pseudocelli 3/011/?1?1

D. vinuensis (Simón-Benito and Luciáñez, 1994) (Spain, surface)

20 Abd V with 3 dorsal pseudocelli ..................................................................... 21

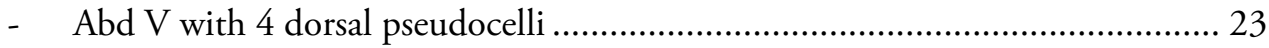

212 ventral head pseudocelli................... D. scotaria (Gisin, 1954) (Europe, surface)

- 3 ventral head pseudocelli.................................................................................. 22

22 Ventral formula of pseudocelli 3/011/3212

D. frasassi (Fanciulli, 1999) (/Italy, cave)

- Ventral formula of pseudocelli 3/022/3222

D. ossaria (Gisin, 1964) (Italy, cave)

232 ventral head pseudocelli

3 ventral head pseudocelli. 26

24 Without ventral pseudocelli on Th II-III.

D. hussoni (Denis, 1935) (Europe, caves)

- With ventral pseudocelli on Th II-III

25 Ventral formula of pseudocelli 2/011/2212

D. ghidinii (Denis, 1938)(Europe, surface)

- Ventral formula of pseudocelli 2/-11/3111

D. handschini (Denis, 1925) (Europe, cave)

26 Th II-III with 2 ventral pseudocelli. D. bosnaria (Gisin, 1964) (Bosnia, soil)

- Th II-III with 1 ventral pseudocellus....

27 Ventral formula of pseudocelli 3/011/2212.

..D. pseudoghidinii (Dallai, 1969) (Italy, soil and cave)

- Ventral formula of pseudocelli 3/011/3212

D. caprelleana Fanciulli, Loreti and Dallai, 2010 (Italy, cave)

28 Th II with 2 dorsal pseudocelli

Th II with 3 dorsal pseudocelli 
29 Th III with 2 dorsal pseudocelli and Abd IV with 4 dorsal pseudocelli D. nevoi (Gruia, Poliakov and Broza, 2000) (Israel, soil)

- Th III and Abd IV with 3 dorsal pseudocelli. D. fazii (Christiansen, 1956) (Lebanon, soil)

30 Abd II-III with 4 dorsal pseudocelli D. bergamaria (Gisin, 1956) (Italy, cave)

- Abd II-III with 3 dorsal pseudocelli ..................................................................31

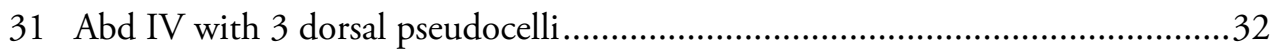

- $\quad$ Abd IV with more than 3 dorsal pseudocelli.....................................................33

32 Ant III sensory organ with 4 papillae

D. jana (Christiansen and Bellinger 1980) (U.S.A and Mexico, cave?)

- Ant III sensory organ with 5 papillae.....

D. paro (Christiansen and Bellinger 1980) (USA and Canada, cave $\&$ soil)

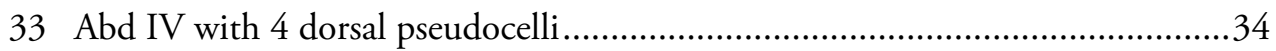

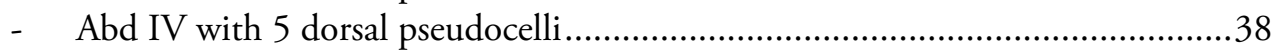

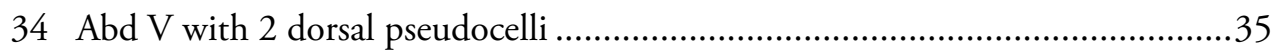

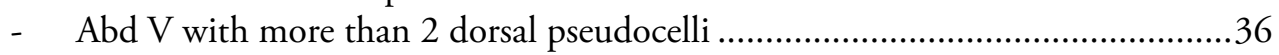

35 Ventral formula of pseudocelli 2/000/2111

D. paro (Christiansen and Bellinger 1980) (USA and Canada, cave \& soil)

- Ventral formula of pseudocelli 3/011/1212

D. angelieri (Izarra, 1968) (France, soil)

36 With more than 25 vesicles in PAO

- With fewer than 21 vesicles in PAO...

D. traiani Gruia and Popa, 2005 (Romania, cave)

$37 \mathrm{PAO}$ with 10 vesicles.

..D. variabilis (Stach, 1954) (Europe, surface)

- PAO with $12-20$ vesicles

D. opa (Christiansen and Bellinger, 1980) (USA and Mexico, surface \& cave)

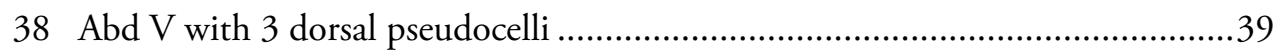

- Abd V with 4 dorsal pseudocelli ......................................................................4

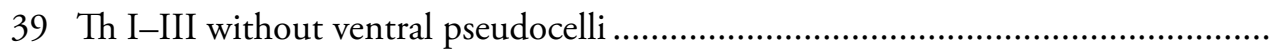

D. eduardi (Denis, 1937) (Italy and France, surface $\&$ cave)

- Th I-III with 011 ventral pseudocelli .................................................................40

40 Abd I-IV with 1212 ventral pseudocelli

- With different formula

D. pseudoinsubraria (Dallai, 1970) (Italy, soil)

41 Abd I-IV with 2212 ventral pseudocelli

D. insubraria (Gisin, 1952) (Europe, surface \& cave) 


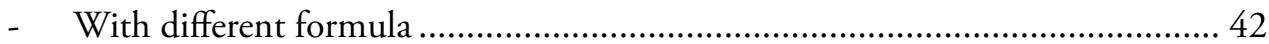

42 Abd I-IV with 3212 ventral pseudocelli ............................................................ 43

- $\quad$ Abd I-IV with 3222 ventral pseudocelli

D. silvaria (Gisin, 1952) (Europe, surface \& cave)

43 Unguiculus with basal lamella, 18-18-17 chaetae on tibiotarsus I, II, III. D. mangazeya Babenko, 2007 (Russia, Siberia, soil)

- Unguiculus without basal lamella, 18-18(20)-18(19) chaetae on tibiotarsus I, II, III....................................... D. gemae (Simón-Benito et al., 1994) (Spain, soil)

44 Head with 2 ventral pseudocelli......................................................................... 45

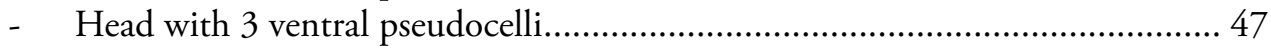

45 Th and Abd without ventral pseudocelli (2/000/0000)

D. antheuili (Denis, 1936) (Europe, surface $\&$ cave)

- Th and Abd with ventral pseudocelli.................................................................. 46

46 Ventral pseudocelli formula 2/011/1212.

D. defensaria (Gisin, 1964) (Italy, cave)

- Ventral pseudocelli formula $2 / 011 / 2212$.

D. imperfecta sensu Denis, 1938 nec Gisin 1952 (Europe, surface \& cave)

47 Abd I with fewer than 3 ventral pseudocelli ................................................... 48

- Abd I with 3 ventral pseudocelli ......................................................................... 49

48 Ventral pseudocelli formula 3/011/0111

D. gigoni (Gisin, 1962) (Europe, cave)

- Ventral pseudocelli formula 3/011/2212.

D. dunaria Gisin, 1956 (Europe, cave)

49 Ventral pseudocelli formula $3 / 011 / 3212$

D. cebennaria (Gisin, 1956) (Europe, cave)

- Ventral Abd I-IV pseudocelli formula 3222 .................................................. 50

50 Unguiculus with basal lamella and subcoxa with 1 pseudocellus

D. banatica (Gruia, 1965) (Romania, cave)

- Unguiculus without basal lamella ............................................................... 51

51 Subcoxa with 2 pseudocelli

D. haybachae (Gisin, 2962) (D. austriaria possible synonym) (Austria, cave)

- Subcoxa with 3 pseudocelli..........D. vercoraria (Gisin, 1963) (Europe, surface)

52 Head with 3 posterodorsal pseudocelli............................................................. 53

- Head with more than 3 posterodorsal pseudocelli............................................. 65

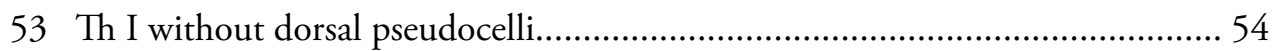

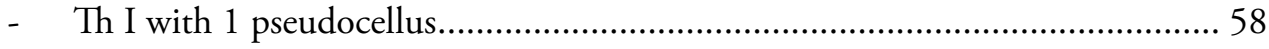

54 Abd V with 3 dorsal pseudocelli ................................................................. 56

- Abd V with 4 dorsal pseudocelli ................................................................... 55 
55 Abd I-II with 4 dorsal pseudocelli.....

D. pseudofimetaria (Folsom, 1917) (USA, cave \& surface)

- $\quad$ Abd I-II with 3 dorsal pseudocelli... D. rendsinae (Haybach, 1962) (Austria, soil)

56 Head with 2 ventral pseudocelli (ventral formula 2/011/)..... 57

- Head with 3 ventral pseudocelli (ventral formula 3/022/3212)...

D. pseudobosnaria (Dallai, 1970) (Italy, soil)

57 Abd I-IV with 1212 ventral pseudocelli

Abd I-IV with 1111 ventral pseudocelli

D. apuanica (Dallai, 1970) (Italy, soil) D. pseudofimetaria (Folsom, 1917) (USA, cave \& surface)

58 Abd IV with 4 dorsal pseudocelli..... D. jitkae (Rusek, 1964) (Slovakia, soil)

- Abd IV with more than 4 dorsal pseudocelli...................................................... 59

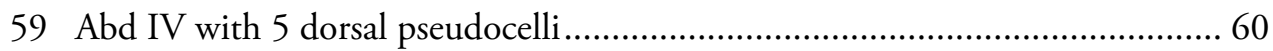
Abd IV with 6 dorsal pseudocelli..... D. harrobiensis (Beruete et al., 2001) (Spain, cave)

60 Abd II with 3 dorsal pseudocelli 62

- Abd II with more than 3 dorsal pseudocelli 61

61 Abd II with 4 dorsal pseudocelli

D. galani (Beruete et al., 2001) (Spain, cave)

- Abd II with 5 dorsal pseudocelli D. boneti (Gisin, 1953) (Spain, cave)

62 Abd V with 3 dorsal pseudocelli D. closanica (Gruia, 1965) (Romania, cave)

- Abd V with 4 dorsal pseudocelli 63

63 Ventral pseudoceli formula 3/011/2112.

D. arminiaria (Gisin, 1961) (Austria, cave)

- With different formula

64 Ventral pseudocelli formula 3/011/3211

D. trisilvaria (Gisin, 1962) (Austria, cave)

- Ventral pseudocelli formula 3/011/4222.

D. kosarovi (Zonev, 1973) (Bulgaria, soil)

65 Head with 4 posterodorsal pseudocelli. 66

- Head with 6 posterodorsal pseudocelli.

D. inferni Gisin, 1956 (Suitzerland, cave)

66 Th I with 1 dorsal pseudocellus

- Th I with 2 dorsal pseudocelli. D. leitzaensis (Beruete et al., 2001) (Spain, cave) 


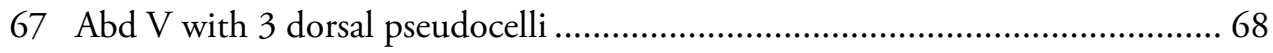

- Abd V with 4 dorsal pseudocelli ...................................................................... 70

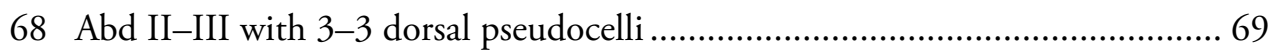

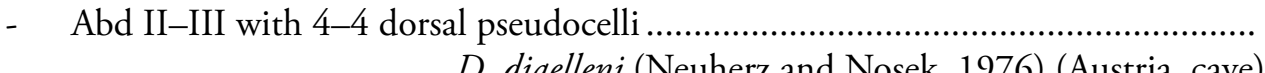

D. diaelleni (Neuherz and Nosek, 1976) (Austria, cave)

$69 \mathrm{PAO}$ with 12 compound tubercles, ventral formula as 3/011/3212....

D. closanica (Gruia, 1965) (Romania, cave)

- PAO with 19-24 compound tubercles, ventral pseudocelli formula 3/011/3111 D. kruberaensis $\mathrm{n} . \mathrm{sp}$.

70 Abd II with 2 dorsal pseudocelli

.. quadrisilvaria (Gisin, 1962) (Austria, cave)

- $\quad$ Abd II with more than 2 pseudocelli .............................................................. 71

71 Abd II with 4 dorsal pseudocelli ............................................................... 72

- Abd II with 5 dorsal pseudocelli ............... D. boneti (Gisin, 1953) ) (Spain, cave)

72 Abd IV with 3 dorsal pseudocelli.....

D. aralarensis (Beruete et al., 2001) (Spain, cave)

- $\quad$ Abd IV with 5-6 dorsal pseudocelli................................................................. 73

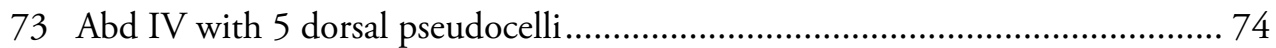

- Abd IV with 6 dorsal pseudocelli ................................................................... 75

74 Abd IV with 1 ventral pseudocellus $(3 / 011 / 2+1111)$

D. doneztebensis (Beruete et al., 2001) (Spain, cave)

- $\quad$ Abd IV with 2 ventral pseudocelli $(3 / 011 / 3+11-21-22)$

D. boneti (Gisin, 1953) (Spain, cave)

75 PAO with 20-24 compound vesicles.

D. diaelleni (Neuherz and Nosek, 1976) (Austria, cave)

- $\quad \mathrm{PAO}$ with fewer than 18 compound vesicles................................................... 76

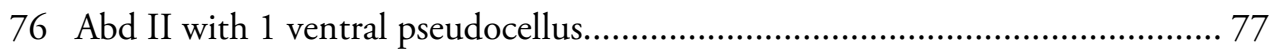

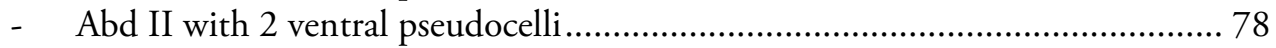

77 Ventral pseudocelli formula 3/011/2+1211

.. D. labainensis (Beruete et al., 2001) (Spain, cave)

- Ventral pseudocelli formula 3/011/3 + 1222 .

D. zalbidensis (Beruete et al., 2001) (Spain, cave)

78 Chaeta $\mathrm{m}_{7}$ present on Th II-III

..D. doneztebensis (Beruete et al., 2001) (Spain, cave)

- Chaeta $\mathrm{m}_{7}$ absent on Th II-III.

..D. ameskoanus (Beruete et al., 2001) (Spain, cave) 


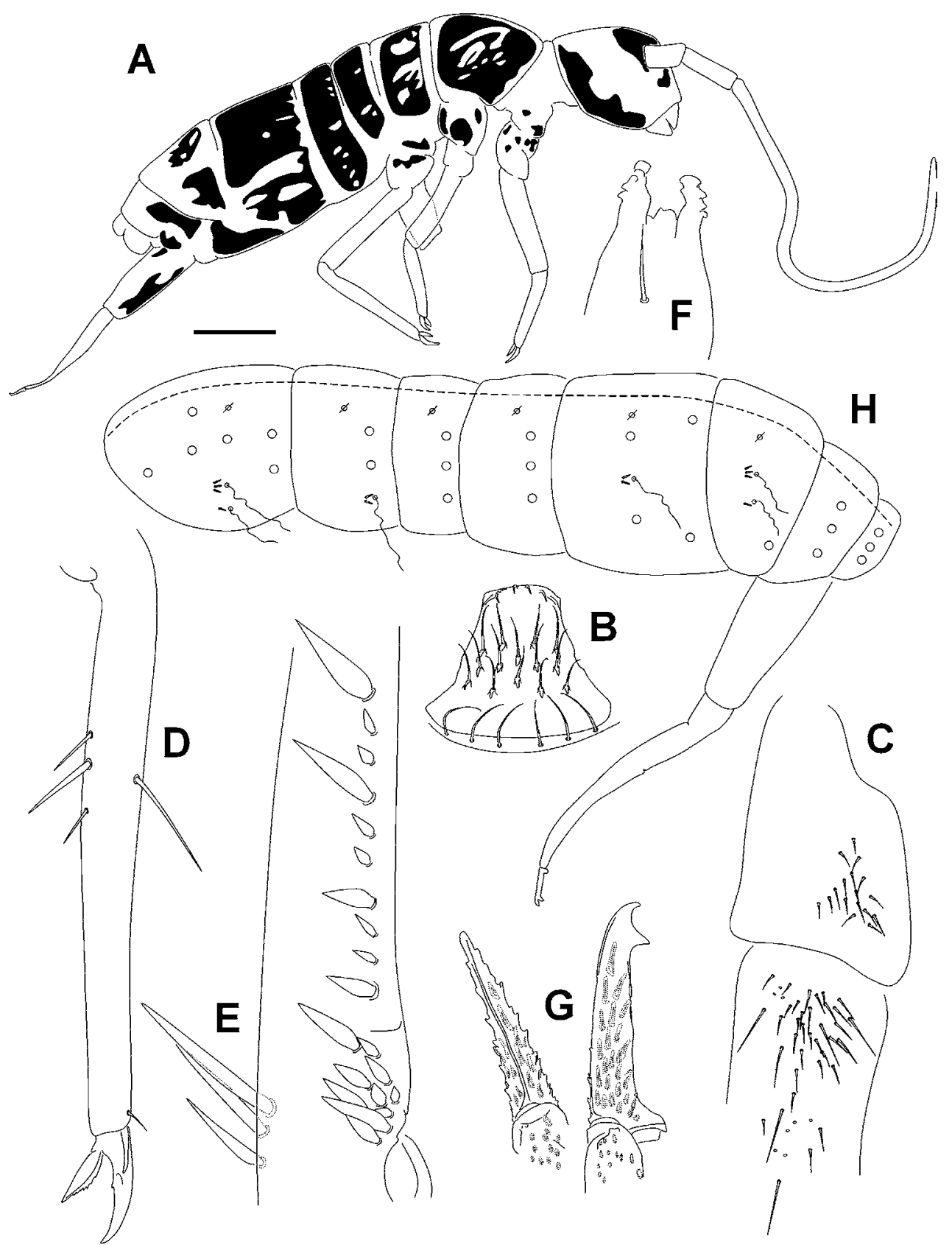

Figure 15. Plutomurus ortobalaganensis n. sp. (A) Lateral habitus showing colour pattern (scale bar: $500 \mu \mathrm{m}$ ). (B) Labrum and prelabral chaetae. (C) Trochanter and basal femur, showing the trochanteral organ. (D) Leg III tibiotarsus, showing the shape of chaetae and spine-like chaeta. (E) Basal dental spines. (F) Tenaculum. (G) Detail of the mucro. (H) Body macrochaetotaxy (Ø, pseudopore; O, macrochaetae). 


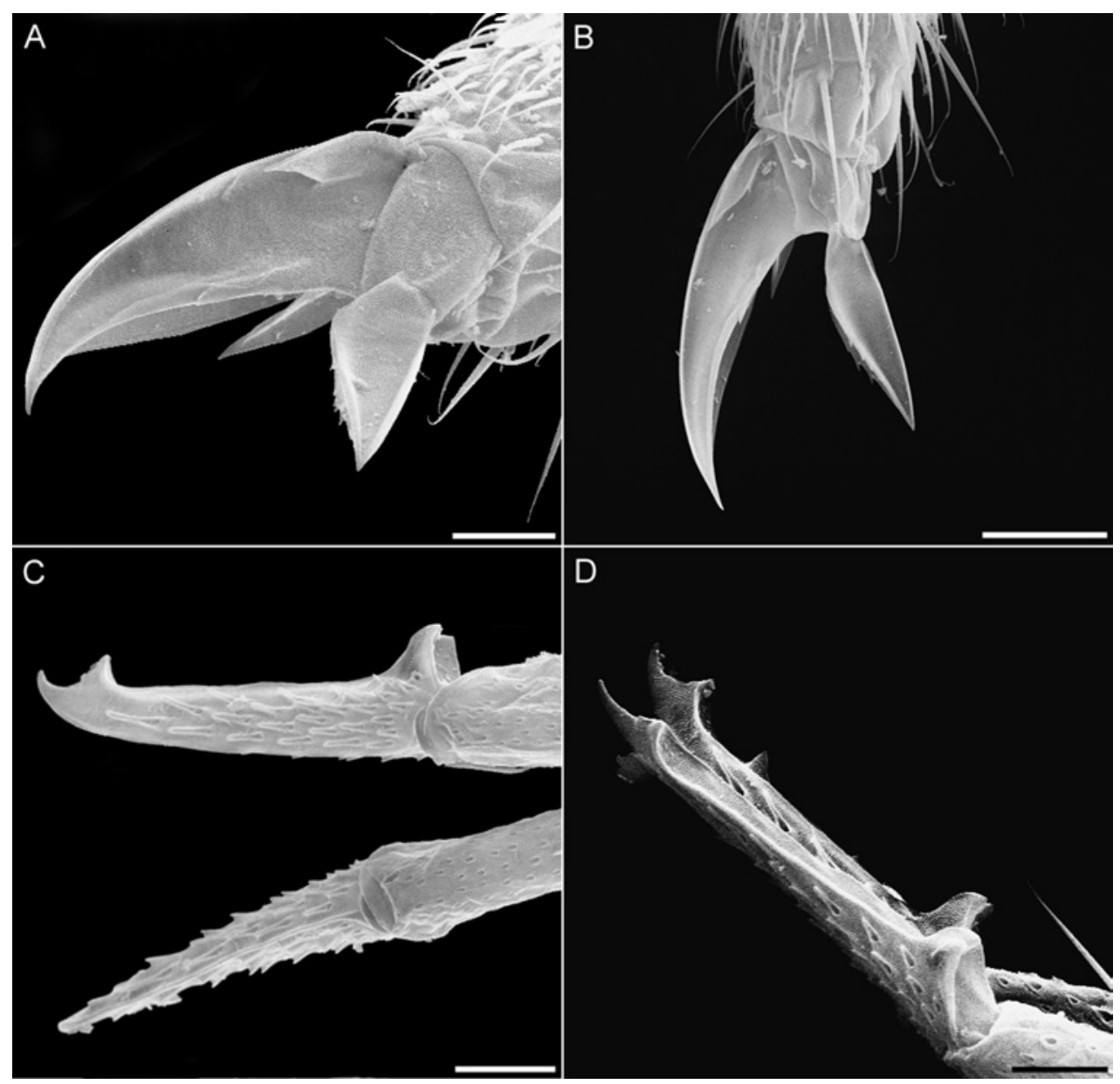

Figure 16. Plutomurus ortobalaganensis $\mathrm{n}$. sp. SEM microphotographs. (A-B) Unguis and unguiculus of leg III. (C-D) Mucro in different views (bars, A, C and D: $20 \mu \mathrm{m}$; B: $40 \mu \mathrm{m}$.

\section{Plutomurus ortobalaganensis Jordana and Baquero n. sp.}

(Figures 15-16)

\section{Type locality}

Krubera Cave (called too Voronya Cave or Voronja Cave), Arabika Massif, Gagrinsky Range of the Western Caucasus, Gagra district of Abkhazia (Ortobalagan).

\section{Type material}

Holotype (female) on slide, $-70 \mathrm{~m}$ from entrance ( $2420 \mathrm{~m}$ above sea level), pitfall trap, between 26.VII.2010 to 24.VIII.2010. Coordinates: lat $43.409722^{\circ}$, long $40.362222^{\circ}$ $\left(43^{\circ} 24^{\prime} 35.00^{\prime \prime N}, 40^{\circ} 21^{\prime} 44.00^{\prime E}\right.$ ). CaveX Team leg. Paratypes: 9 from $-70 \mathrm{~m}$ (one female on slide, one on SEM stub and 7 in ethyl alcohol); 4 from $-1980 \mathrm{~m}$ (ethyl 


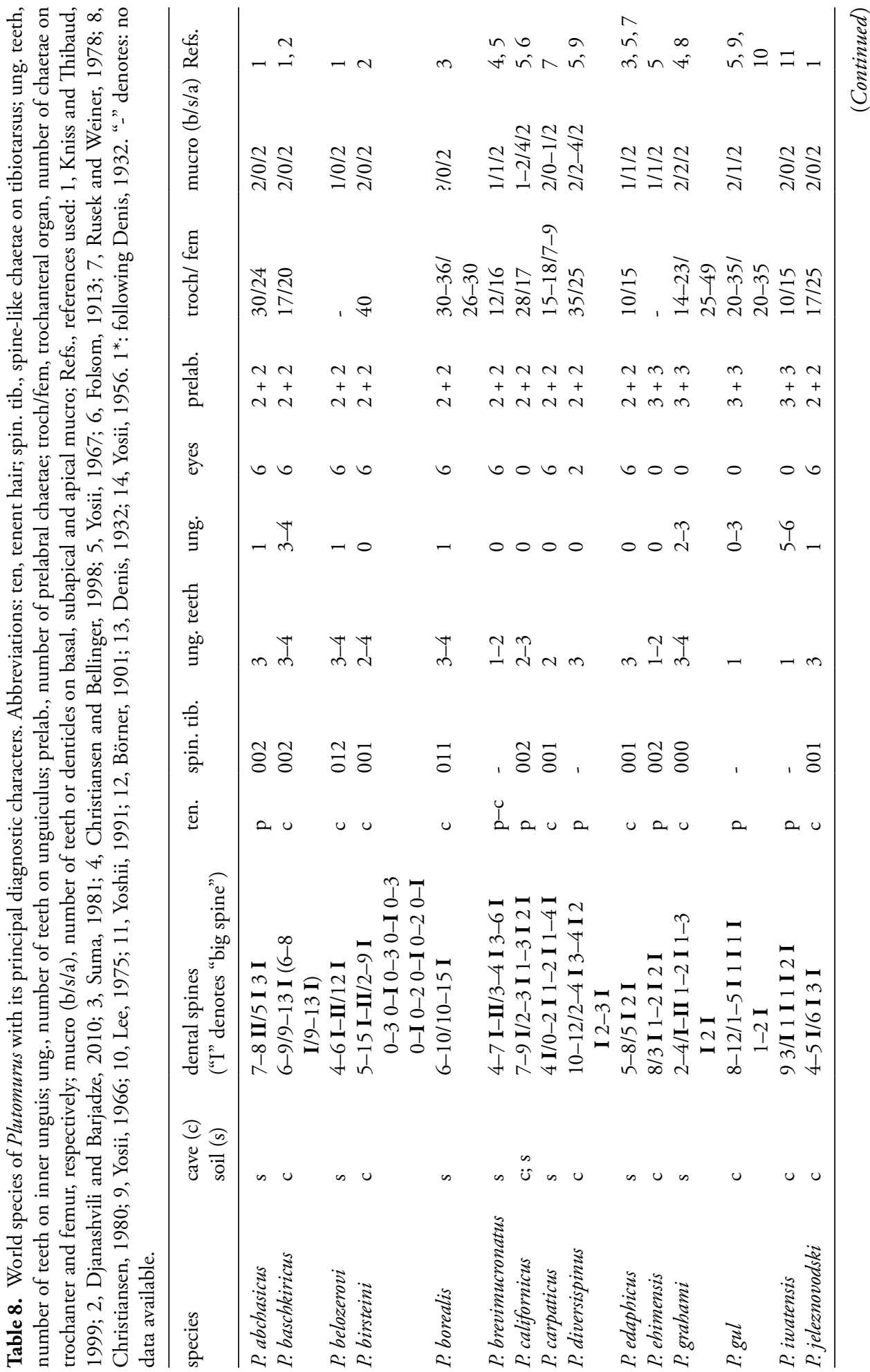




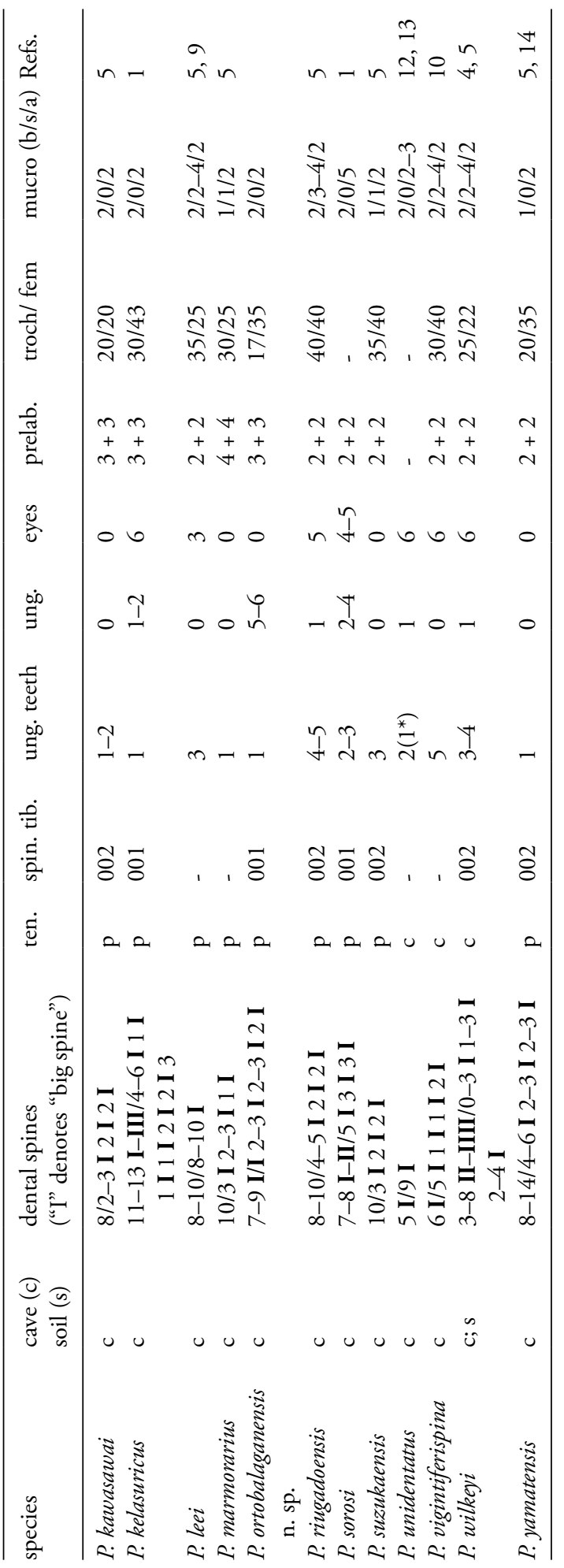


alcohol). Deposited in Museu de Valencia (Holotype and 3 Paratypes) and MZNA (2 Paratypes).

\section{Etymology}

From Ortobalagan, meaning "nearby settlement".

\section{Description}

Body length up to $3.8 \mathrm{~mm}$ excluding antennae (mean 3.0 with $\mathrm{n}=16$ ). Body background greyish, with patches of darker pigmentation over the whole body except on antennae, legs (trochanter to tibiotarsi) and dentes; colour pattern as in Figure 15A.

Head. Eye patch small, divided into two subpatches but without exterior corneoles (as seen with SEM). Ratio body/antennae length $0.8(\mathrm{n}=2)$. Prelabral chaetae: $3+3$, labrum 5, 5, 4 and 4 curved chaetae on distal part of labrum (Figure 15B).

Body. Trochanteral organ well developed on trochanter and femur, with $17 / 40$ chaetae respectively, a few chaetae longer than the rest (Figure 15C). Ventral tube with 35-40 chaetae. Spine-like chaetae absent on tibiotarsus I and II, 1 such chaeta on tibiotarsus (formula 001) (Figure 15D). Unguis with 1 or 2 internal teeth (if 2, paired), at $40 \%$ of the unguis length from the base of unguis; unguiculus blade-like, with serrate external edge after middle point, and almost to its tip (Figure 16A-B); tenent hair very short, pointed ( 0.27 times length of unguis). Ratio of unguis, unguiculus and tenent hair 17:10:5. Unguis with a thin pseudonychia, 0.42 times length of inner edge of unguis. Tenaculum with $4+4$ teeth and 1 chaeta on corpus (Figure 15F). Ratio of manubrium, dens and mucro $5.4: 8.6: 1$. Outer margin of dens with 3 thick spine-like chaetae. Dental formula: 7-9 I/ I 2-3 I 2-3 I 2 I (dental big spines in Roman and bold) (Figure 15E). Mucro with 2 basal, fused denticles, without subapical denticles, and 2 distal teeth (Figures 15G, 16C-D).

\section{Chaetotaxy}

Macrochaetotaxy and trichobothrial patterns in Figure 15H. Dorsal macrochaetae: Th II-III with 6-2 macrochaetae respectively; Abd I-VI with 3-3-4-1-3-3 macrochaetae respectively. Trichobothrial formula $0 / 2-1 / 0-0-1-2-0$. Trichobothrium with 1-3 small anterior chaetae.

\section{Discussion}

Of the 26 known Plutomurus spp. (Table 8) 9 lack eyes altogether. Plutomurus ortobalaganensis n. sp. differs from these 9 species by the following combination of characters: $3+3$ prelabral chaetae; subapical denticles lacking on mucro; unguiculus with internal teeth, and dental spine formula 7-9 I / I 2-3 I 2-3 I 2 I. Five of the 9 species have $3+3$ prelabral chaetae, but only 2 of the 5 have a similar mucronal denticles formula: 2/0/2 (basal/subapical/apical); $P$. kawasawai has no denticles on unguiculus. The remaining species, $P$. iwatensis, can be distinguished by its dental spine formula (9 3/I 1 I 1 I 2 I) and the trochanteral organ (10/15 chaetae on trochanter and femur 
respectively). Three Plutomurus spp. have been described from Georgia (P. abchasicus, P. birsteini and P. kelasuricus), but all have six eyes on each side.

Key to the world species of Plutomurus

(In the dental spine formula "I" denotes "large spine").

1 With 6 eyes on each side of the head ................................................................ 2

- With fewer than 6 eyes ........................................................................... 14

2 With subapical denticles on mucro.................................................................. 3

- Without subapical denticles on mucro.......................................................... 7

3 Two to four subapical denticles on mucro........................................................ 4

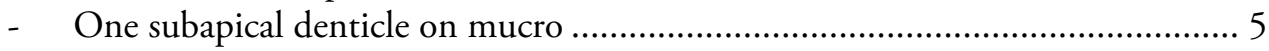

4 Unguiculus without tooth ........... vigintiferispina Lee, 1974 (South Korea, cave)

- Unguiculus with 1 tooth ....................... wilkeyi Christiansen, 1964 (USA, cave)

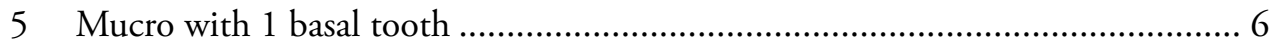

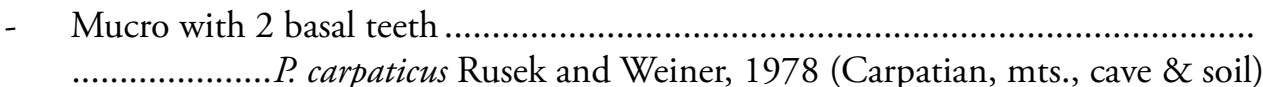

6 Unguis with 1-2 internal teeth; dental spine formula 4-7 I-II/3-4 I 3-6 I P. brevimucronatus Denis, 1928 (USA, soil and cave)

- Unguis with 3 internal teeth; dental spine formula 5-8/5 I 2 I. P. edaphicus Yosii, 1967 (Japan, soil)

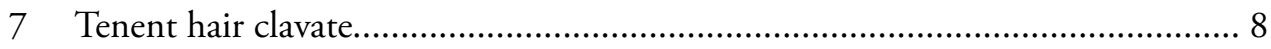

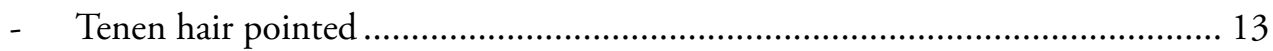

8 Unguiculus without internal tooth

P. birsteini Djanashvili and Barjadze, 2011 (Georgia, cave)

- Unguiculus with internal tooth...................................................................... 9

9 Dental spine formula 5 I/9 I............ P. unidentatus (Börner, 1901) (Europe, cave)

- Different dental spine formula....................................................................... 10

10 Spine-like chaetae on tibiotarsus I, II and III: 011

..P. borealis Suma, 1981 (Japan, soil)

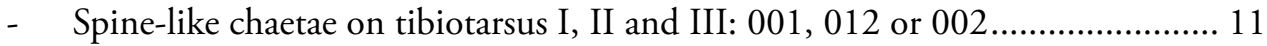

11 Mucro with 1 basal tooth; dental spine formula 4-6 I -2/12 I; one spine-like chaeta on tibiotarsi II and two on tibiotarsi III P. belozerovi Martynova, 1977 (Sakhalin Isl. Russia, soil)

- Mucro with 2 basal teeth............................................................................ 12

12 One spine-like chaeta on tibiotarsus III; dental spine formula 4-5 I /6 I 3 I. .P. jeleznovodski Kniss and Thibaud, 1999 (Caucasus, Russia, cave) 
- Two spine-like chaetae on tibiotarsus III; dental spines formula 6-9/9-13 I... P. baschkiricus (Skorikov, 1900) (Europe, cave)

13 One spine-like chaetae on tibiotarsus III; prelabral chaetae $3+3$.

P. kelasuricus Martynova, 1969 (Georgia, cave)

- Two spine-like chaetae on tibiotarsus III; prelabral chaetae $2+2$. P. abchasicus Martynova, 1969 (Abkhazia, cave)

14 With 4-5 eyes

With fewer than 4 eyes

15 With 3 or 4 subapical denticles on mucro

P. riugadoensis (Yosii, 1939) Yosii, 1956 (Japan, cave)

- Without subapical denticles on mucro.

P. sorosi Kniss and Thibaud, 1999 (Russia, cave)

16 With 3 eyes P. leei Yosii, 1966 (South Korea, cave)

- Without or with 2 eyes

17 With 2 eyes P. diversispinus Yosii, 1966 (South Korea, cave) Without eyes

18 Prelabral chaetae $4+4$. P. marmorarius Yosii, 1967 (Japan, cave)

- Prelabral chaetae $2+2$ or $3+3$

19 Prelabral chaetae $3+3$ 20

- Prelabral chaetae $2+2$ 25

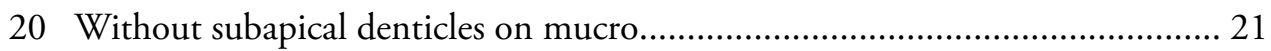

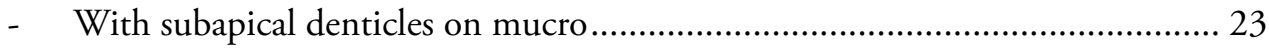

21 Unguiculus without internal tooth ............ . kawasawai Yosii, 1956 (Japan, cave)

- Unguiculus with internal tooth.

22 Dental spine formula 9 3/ I 1 I 1 I 2 I.......... . iwatensis Yosii, 1991 (Japan, cave) - $\quad$ Dental spine formula 7-9 I / I 2-3 I 2-3 I 2 I............... ortobalaganensis n. sp.

23 Unguis with 3 or 4 internal teeth.

P. grahami Christiansen, 1980 (USA, cave \& soil)

- Unguis with 1 or 2 internal teeth.......................................................... 24

24 Dental spine formula 8/3 I 1-2 I 2 I ......... P. ehimensis Yosii, 1956 (Japan, cave)

- Dental spine formula 8-12/1-5 I 1 I 1 I 1-2 I. P. gul Yosii, 1956 (South Korea, cave)

25 Without subapical denticles on mucro...... P. yamatensis Yosii, 1956 (Japan, cave)

- With subapical denticles on mucro...................................................... 26

26 With 1 subapical denticle on mucro..........P. suzukaensis Yosii, 1956 (Japan, cave)

- With 4 subapical denticles on mucro. P. californicus (Folsom, 1913) (California, cave). 


\section{Acknowledgements}

We express our gratitude to the CaveX Team, especially to Sergio Garcia-Dils, Pilar Orche and to Javier Le Pera for their kind support and cooperation in sampling. All specimens were collected under the permit of Abkhazia government, included in the CaveX Ibero-Rusian Team Expedition, from July to August of 2010. Kenneth Christiansen and several anonymous reviewers provided excellent comments and suggestions that improved this manuscript.

\section{References}

Babenko, A.B. 1997. The taxonomy and distribution of the genus Anurida (Collembola: Neanuridae) in the northern Palaearctic. European Journal of Entomology 94:511-536.

Babenko, A.B. 1998. New palaearctic species of the genus Anurida (Collembola, Neanurida). Zoologichesky Zhurnal 77(6):648-661.

Babenko, A.B. 1999. New springtail species of the family Hypogastruridae from Eastern Siberia. Zoologichesky Zhurnal 78:885-888.

Babenko, A.B., Chernova, N.M., Potapov, M.B. and Stebaeva, S.K. 1994. Collembola of Russia and adjacent countries: Family Hypogastruridae. Nauka Publishing House. Leningrad, Russia. 336 pp.

Bellinger, P. F., Christiansen, K. A., Deharveng, L. and Janssens, F. 1996-2011. Checklist of the Collembola of the World. URL: http://webhost.ua.ac.be/collembola/key/neanidae.htm.

Beruete, E., Arbea, J.I. and Jordana, R. 2001. Nuevas especies cavernícolas del género Onychiurus del grupo de O. boneti Gisin, 1953 (Collembola: Onychiuridae) del karst de Navarra y Gipuzkoa (España). Boletín de la Asociación Española de Entomología 25(1-2):9-33.

Bonet, F. 1930. Remarques sue les Hypogastruriens cavernicoles avec descriptions de espèces nouvelles. Eos, Revista Española de Entomología 6:113-139.

Bonet, F. 1945. Nuevos Generos y Especies de Hipogastruridos de Mexico (Collembola). Revista de la Sociedad Mexicana de Historia Natural 6(2):13-45.

Börner, C. 1901. Über einige theilweise neue Collembolen aus den Höhlen der Gegen von Letmathe in Westfalen. Zoologische Anzeiger 24(645):333-345.

Cassagnau, P. 1954. Faune française des Collemboles. III. Poduromorphes de haute montagne. Vie et Milieu 4(1):65-74.

Cassagnau, P. 1955. Sur un essai de classification des Neanuridae holarctiques et sur quelques espèces de ce groupe (Collembola). Revue française d'Entomologie 22(2):134-163.

Cassagnau, P. 1959a. Faune Française des Collemboles (X) Espèces Nouvelles ou peu Connues des Pyrénées et du Sud-Ouest. Vie et Milieu 10(1):68-88.

Cassagnau, P. 1959b. Faune française des Collemboles IX. Les Hypogastrura a. 1. du Massif du Néouvielle (Hautes-Pyrénées). Remarques sur chetotaxie des espèces. Vie et Milieu 9(4):476-503.

Christiansen, K. and Bellinger, P. 1998. The Collembola of North America, North of the Rio Grande. A taxonomic analysis. Part 3. Grinell College Iowa. Pp. 877-1173.

Christiansen, K. 1980. A new nearctic species of the genus Tomocerus (Collembola: Entomobryidae). Proceedings of the Iowa Academy of Sciences 87:121-123.

Dallai, R. and Martinozzi, I. 1980. Ricerche sui Collemboli XXV. La Val di Farma. Atti della Accademia delle Scienze di Siena detta de Fisiocritici, Serie XIV 12. 51 pp.

Dallai, R. 1969. Ricerche sui Collemboli. VI. Le Isole de Capraia di Pianosa. Redia 51:277-304.

Dallai, R. Sabatini, M.A.1981. Ricerche Sui Collemboli XXVIII. Su di una nuova specie endogea di Schaefferia. Redia 64:195-204.

Deharveng, L. 2004. Recent advances in Collembola systematics. Pedobiologia 48:415-433.

Deharveng, L. and Thibaud, J.-M. 1980. Trois espèces nouvelles du genre Schaefferia Absolon, 1900 (Insecte, Collembole). Nouvelle Revue d'Entomologie 10:3-10. 
Delamare-Deboutteville, C. 1945. Sur quelques Collemboles de la région de Banyuls (Pyrénées-Orientales) avec la description d'une espèce troglobie. Bulletin de la société entomologique de France 6:70-72.

Denis, J.R. 1932. Sur la faune française des Aptérygotes. XII. Archives de Zoologie Expérimentale et Générale, 74:357-383.

Djanashvili, R. and Barjadze, S. 2010. A new species of the genus Plutomurus Yosii, 1956 (Collembola, Tomoceridae) from Georgian caves. Journal of Cave and Karst Studies 73(1):28-30.

Dunger, W. 1974. Neue und bemerkenswerte Collembolenarten der Familie Neanuridae Abhandlungen und Berichte des Naturkundemuseums Görlitz 5:1-20.

Fjellberg, A. 1973. Anurida frigida. A New Species of Collembola (Hypogastruridae) from Swedish Lappland. Norsk Entomologisk Tidsskrift 20:285-287.

Fjellberg, A., 1985. Arctic Collembola. I - Alaskan Collembola of the families Poduridae, Hypogastruridae, Odontellidae, Brachystomellidae and Neanuridae. Entomologica Scandinavica 21:1-126.

Fjellberg, A. 1998. The Collembola of Fennoscandinavia and Denmark. Part I. Poduromorpha. Fauna Entomologica Scandinavica 35: 1-184.

Fjellberg, A. 1999. Labial palp in Collembola. Zoologischer Anzeiger 237:309-330.

Folsom, J.W. 1913. North American springtails of the subfamily Tomocerinae. Proceedings of the United States National Museum 46(2037):451-472.

Gama, M.M. da. 1963. Quatre espèces nouvelles de Collemboles d'Autriche et de Jougoslavie Archives des Sciences (Genève) 16:43-50.

Gisin, H. 1953. Notes sur les Collemboles, avec description de cinq espèces nouvelles découvertes dans le canton de Genève. Mitteilungen Schweizerischen Entomologischen Gesellschaft 24(1):56-62.

Gisin, H. 1962. Sur la faune européenne des Collemboles IV. Revue Suisse de Zoologie 69(1):1-23.

Gruia, M. 1965. Nouvelles espèces de Collemboles cavernicoles de Roumanie. Review Roumain de Biologie-Zoologie 10(2):103-110.

Harsia, T. and Gruia, M.1992. A new species of the genus Anurida Laboulbene, 1985 (Collembola, Neanuridae) from Romania. Travaux de l'Institut de Spéologie "Émile Racovitza" 31:65-67.

Jordana, R. and Arbea, J.I. 1990. Especies ibéricas de Hypogastrura (Ceratophysella) de seis ojos con descripción de tres nuevas especies (Collembola, Hypogastruridae). Graellsia 46:161-173.

Jordana, R., Arbea, J.I., Simón, C. and Luciáńez, M.J. 1997. Collembola, Poduromorpha. In: Ramos, M.A. et al. (eds.). Fauna Ibérica, vol. 8. Museo Nacional de Ciencias Naturales. CSIC. Madrid, España. 807 pp.

Kniss, V. and Thibaud, J.M. 1999. Le genre Plutomurus en Russie et en Géorgie (Collembola, Tomoceridae). Revue française d'Entomologie (N.S.) 21(2):57-64.

Lee, B.H. 1975. Etude de la faune coréenne des Insectes Collemboles VI. Sur la famille des Tomoceridae, édaphiques avec la description de quatre nouvelles espèces et d'une nouvelle sous-espèce. Bulletin du Muséum National d'Histoire Naturelle 3(317):945-961.

Martynova, E.F. 1978. New species of Springtails of the genus Hypogastrura s. 1. in the North-Eastern Asia Fauna. Novye I Maloizvestnye Vidy Fauny Sibiri 12:27-47.

Neuherz, H. and Nosek, J. 1976. Onychiurus (Onychiurus) diaelleni sp. n., eine neue Collembolenart aus der "Raudner-Höhle" (Steiermark). Mitteilungen des Naturwissenschaftlichen Vereines für Steiermark 106:209-214.

Palacios-Vargas, J.C. and Thibaud, J.-M. 1985. Nuevos Hypogastruridae anoftalmos (Collembola) de cuevas y suelos de México. Folia Entomologica Mexicana 66:3-16.

Palacios-Vargas, J.G. and Castaño-Meneses, G. 2008. A new species of Schaefferia Absolon, 1900 (Collembola: Hypogastruridae). Dugesiana 15(2):123-125.

Rusek, J. 1970. Zwei neue Collembolen-Arten von den šberschwemmungswiesen in Südmähren. Véstník Československé Společnosti Zoologické (Acta Societatis Zoologicae Bohemoslovacae) 4:309-316

Rusek, J. and Weiner, W. M. 1978. Plutomurus carpaticus sp. n. (Collembola: Tomoceridae) from the Carpathian Mountains. Bulletin de l'Académie Polonaise des Sciences Série des Sciences Biologiques Cl. II, 25:741-747. 
Stach, J. 1939. Die Hohlenfauna des Glatzer Schneeberges. II Die Collembolenfauna der Salzlochêr bei Seitendorf. Beitrage zur Biologie des Glatzer Schneeberg 5:395-415.

Steiner, W. 1955. Beiträge zur Kenntnis der Collembolenfauna Spaniens. Eos 34:323-340.

Suma, Y. 1981. A new humicolous species of Plutomurus (Collembola, Tomoceridae) from Hokkaido, North Japan. Kontyu 3:502-505.

Tamura, H. and Zhao, L. 1997. Two new species of the family Pseudachorutidae from Mt. Jizu, western Yunnan, southwest China (Insecta: Collembola). Natural History Bulletin of Ibaraki University $1: 45-50$.

Thibaud, J.-M. 1972. Révision du Genre Schaefferia Absolon, 1900 (Insecte, Collembole) Annales de Spéléologie 27(2):363-394.

Thibaud, J.-M. 1995. Une nouvelle espèce de Schaefferia d'une grotte des Etats-Unis d'Amérique (Collembola, Hypogastruridae). Revue Française d'Entomologie (Nouvelle Série) 17(2):77-78.

Thibaud, J.-M. and Massoud, Z. 1986. Un nouveau genre d'Insectes Collemboles Onychiuridae cavernicoles des Picos de Europa (Espagne). Bulletin Du Muséum National D’histoire Naturelle Section A Zoologie Biologie et Ecologie Animales 8(2):327-331.

Thibaud, J.-M., Schulz, H.J. and Gama, M.M. da. 2004. Hypogastruridae. In: Dunger, W. (ed.). Synopses on Palaearctic Collembola, Vol. 4. Staatliches Museum für Naturkunde Görlitz, Germany, 287 pp.

Tshelnokov, V.G. 1988. New species of the springtail genus Anurida Laboulb. (Collembola, Neanuridae) from the Asiatic part of the USSR. Entomologischekoe Obozr 67(1):68-87.

Weiner, W.M. 1996. Generic revision of Onychiurinae (Collembola: Onychiuridae) with a cladistic analysis. Annales de la Société Entomologique de France, N.S. 32:163-200.

Wray, D.L. 1963. Collembola of North America; Part I, Hypogastrurinae. Journal of the Tennessee Academy of Science 38(3):101-104.

Yoshii, R. 1991. About the proserpinae group of Hypogastrura (Collembola) in the Caves of Pref. Iwate. Annals of the Speleological Research Institute of Japan (Iwaizumi) 9:3-10.

Yosii, R. 1954. Hohlencollembolen Japans I. Konatyu 20(3-4):62-70.

Yosii, R. 1956. Monographie zur Höhlencollembolen japans. Contributions from the Biological Laboratory Kyoto University 3:1-109.

Yosii, R. 1966. Results of the Speleological Survey in South Korea 1966. IV. Cave Collembola of South Korea. Bulletin of the National Science Museum 4:541-561.

Yosii, R. 1967. Studies on the Collembolan family Tomoceridae, with special reference to Japanese forms. Contributions from the Biological Laboratory Kyoto University 20:1-54.

Yosii, R. 1970. On some Collembola of Japan and adjacent Countries. II. Contributions from the Biological Laboratory Kyoto University 23:1-32.

Yue, Q.-Y. and Yin W. 1999. Two new species of collembola (Arthropleona: Neanuridae, Pseudachorutidae) from Shanghai, China. Entomologia Sinica 6(3):222-226. 